\title{
O problema de Lurie e aplicações às redes neurais
}

\author{
Rafael Fernandes Pinheiro
}

DISSERTAÇÃO APRESENTADA

$\mathrm{AO}$

Instituto de MatemáticA E EstatísticA

DA

Universidade DE SÃo PAUlo

PARA

OBTENÇÃO DO TÍTULO

$\mathrm{DE}$

Mestre EM CiênCIAS

Programa: Matemática Aplicada

Orientador: Prof. Dr. Pedro Aladar Tonelli 


\section{O problema de Lurie e aplicações às redes neurais}

Esta versão da dissertação contém as correções e alterações sugeridas pela Comissão Julgadora durante a defesa da versão original do trabalho, realizada em 12/03/2015. Uma cópia da versão original está disponível no

Instituto de Matemática e Estatística da Universidade de São Paulo.

Comissão Julgadora:

- Prof. Dr. Pedro Aladar Tonelli (orientador) - IME-USP

- Prof. Dr. Manuel Valentim de Pera Garcia - IME-USP

- Prof. Dr. Laécio Carvalho de Barros - IMECC - UNICAMP 


\section{Agradecimentos}

Neste momento tão especial é hora de externar meus sinceros agradecimentos àqueles que embora não tenham o nome na capa, fizeram com que esse trabalho fosse possível.

Agradeço, primeiramente, Àquele que considero o "equilíbrio absolutamente estável" do ser humano: o Pai, o Filho Jesus e o Espírito Santo. Obrigado Senhor por mais essa dádiva em minha vida.

À minha amada esposa Elaine, que sempre esteve ao meu lado incentivando, apoiando e me suportando nos momentos de dificuldades.

À minha filha amada Isabelle, que é minha motivação, minha alegria, meu tesouro.

Ao meu pai, minha mãe, minhas irmãs e toda família que sempre torceram por mim e me apoiaram.

Ao meu querido amigo e orientador Prof. Pedro, o qual desde 2007 vem me ensinando e motivando.

Aos professores Manuel e Sônia Garcia, personagens que sempre estiveram por perto me orientando e ouvindo em momentos importantes.

Aos meus queridos da MTVIDAS e IMOSP, pelas preciosas orações, incentivo irrestrito e carinho.

Aos companheiros da Força Aérea Brasileira, os quais sempre compreenderam meus sonhos e me apoiaram.

Aos meus alunos, com os quais sempre aprendo.

A todos que de forma direta ou indireta contribuíram para minha chegada até esse precioso momento, meus sinceros agradecimentos. 


\section{Resumo}

Neste trabalho apresentamos um assunto que tem contribuído em diversas áreas, o conhecido Problemas de Lurie. Para exemplificar sua aplicabilidade estudamos a Rede Neural de Hopfield e a relacionamos com o problema. Alguns teoremas são apresentados e um dos resultados do Problema de Lurie é aplicado ao modelo de Hopfield.

Palavras-chave: Problema de Lurie, Estabilidade Absoluta, Rede Neural de Hopfield, Funções de Lyapunov. 


\section{Abstract}

In the present work we show some properties of the so called Lurie's type equation. We treat particularly the stability condition's problem, and show how this theory is applied in a Hopfield neural network.

Keywords: Lurie Problem, Absolute Stability, Hopfield Neural Network, Lyapunov functions. 


\section{Prefácio}

Viajando ao longo dos anos desde a década de 40 a partir de um sistema de controle automático de aeronaves até aplicações em áreas complexas que são alvos de muitos estudos, como por exemplo o cérebro humano, o conhecido Problema de Lurie, do matemático A. I. Lurie, tem feito sua história. Com uma colaboração significativa na Matemática Aplicada, em subáreas como teoria de estabilidade e controle e também lançando as bases para uma nova e importante área, Controle Robusto, o Problema de Lurie tem surpreendido cada vez mais em possibilidades de aplicações. Um problema que colaborou também para o crescimento de muitas outras teorias, como a Teoria da Estabilidade de Lyapunov, ainda não tem por completa sua solução, devido, entre outras coisas, a complexidade desde o ponto de sua compreensão inicial, até o ponto em que milhares de trabalhos surgem. Porém permanece a necessidade de resultados para casos mais gerais que tragam condições necessárias e suficientes para estabilidade absoluta.

Por um outro lado desse trabalho temos a Rede Neural de Hopfield (RNH) que é um modelo de rede neural, proposto por J. J. Hopfield em 1982, que faz parte da área conhecida como Neurodinâmica. A rede de Hopfield tem sido aplicada de forma considerável em diversas áreas. Atualmente revela-se por grande interesse teórico, biológico e outras aplicações como por exemplo em problemas de otimização.

As motivações para os assuntos abordados nessa dissertação nasceram a partir de uma Iniciação Científica realizada no ano de 2007, que teve como tema "Estabilidade de Sistemas Dinâmicos em Dimensão 2 e os Problemas de Aizerman e Lurie no Plano", orientado pelo Prof. Dr. Pedro Aladar Tonelli (IME-USP). Em sequência e como fruto daquela Iniciação Ciêntífica, veio o Trabalho de Conclusão de Curso em 2010, "O Problema de Aizerman em Dimensão 2 e um Contraexemplo em Dimensão 4", o qual em suas sugestões de pesquisas futuras constava que o Problema de Aizerman seria um caso particular do Problema de Lurie sugerindo a pesquisa nessa área, assim, o Problema de Lurie faz parte desse trabalho, acompanhado de inspirações advindas do curso de mestrado, onde foram realizadas disciplinas tanto no IME, quanto na POLI, na área engenharia de sistemas. Então, com um apoio especial do Prof. Dr. Luiz Henrique Alves Monteiro da POLI, surgiu a possibilidade de um trabalho para relacionar o Problema de Lurie com a RNH, possibilidade essa que se fez mais real após a descoberta do artigo de Liao X.X. [20] que agregado a [17, 18] tem um papel de extrema contribuição para a viabilização da dissertação.

Em relação aos objetivos, o primeiro é apresentar de forma clara o Problema de Lurie, pois na pesquisa inicial sobre o tema verificamos que muitos trabalhos citam o problema, e diversos resultados têm sido apresentados. Porém, é difícil encontrar textos que explicam a ideia básica do problema de forma mais ampla e com exemplos. O segundo objetivo é estudar a RNH para compreender melhor o complexo comportamento assintótico da rede, relacionando-a com a estabilidade no sentido de Lyapunov e o Princípio de Invariância de LaSalle. O terceiro e último objetivo é 
relacionar a RNH com o Problema de Lurie fazendo uma aplicação e constatar de fato que a RNH é um caso especial do Problema de Lurie ratificando a tese de que é possível utilizar a teoria de Lurie no estudo da estabilidade da RNH e vice-versa.

Embora esse trabalho trate principalmente de um problema ainda em aberto, o Problema de Lurie, procuramos trazer outros problemas ainda não resolvidos por completo que são relacionados ao Problema de Lurie, bem como, problemas resolvidos integralmente e teorias sólidas que nos servem de ferramentas para o desenvolvimento da dissertação.

Acreditamos que esse trabalho venha contribuir para a divulgação do Problema de Lurie firmando, de fato, os diversos conceitos das bibliografias apresentadas. Pelo fato do Problema de Lurie estar se manifestando como uma boa ferramenta para aplicação em diversas áreas, essa dissertação pode contribuir também por meio dos teoremas apresentados, que trazem condições explícitas para estabilidade absoluta que servem como parâmetros para engenheiros. Esperamos contribuir no sentido de firmar os conceitos originais da Rede Neural de Hopfield, onde, com o passar dos anos, acabaram se perdendo. Enfim, dentre as diversas contribuições que esse trabalho pode apresentar, esperamos que acrescente o entendimento e o conhecimento do leitor na teoria da estabilidade.

Para um melhor entendimento, dividimos o trabalho em três capítulos. No primeiro capítulo temos a apresentação das diversas ferramentas que serão utilizadas ao longo do trabalho. No segundo apresentamos o Problema de Lurie em sua forma elementar, ou seja, para um único controle, onde é considerado nesse caso o problema resolvido por completo. No último capítulo temos a apresentação do Problema de Lurie com múltiplos controles, apresentamos a RNH, fazemos sua análise e aplicamos um teorema que surgiu a partir de pesquisas relacionadas ao Problema de Lurie, com isso, possibilitando uma compreensão geral do trabalho dessa aplicação nem tanto trivial. Logo após o último capítulo, algumas considerações finais são elencadas.

Por fim, procuramos fazer este trabalho de modo que pessoas com conhecimentos básicos de álgebra linear, cálculo e EDO possam compreender o conteúdo aqui exposto. Entretanto, para quem possui conhecimentos um pouco mais avançados em EDO e teoria da estabilidade e controle numa abordagem moderna, poderá acompanhar este texto de forma bastante crítica. Desejamos a todos uma boa leitura! 


\section{Sumário}

Lista de Figuras $\quad$ xiii

1 Conceitos Preliminares $\quad 1$

1.1 Estabilidade no Sentido de Lyapunov . . . . . . . . . . . . . . . . . . . . . 1

1.2 Estabilidade para Sistema Lineares . . . . . . . . . . . . . . . . . . . . 3

1.3 Funções de Lyapunov . . . . . . . . . . . . . . . . . . . . . . . . . . . 5

1.4 Um Pouco Mais Sobre o Método Direto de Lyapunov . . . . . . . . . . . . . . . . 7

1.5 O Princípio da Invariância de LaSalle . . . . . . . . . . . . . . . . . . 8

1.6 Estabilidade para Sistemas Não Lineares . . . . . . . . . . . . . . . . . . 11

2 O Problema de Lurie $\quad 15$

2.1 Sistema de Controle Tipo Lurie . . . . . . . . . . . . . . . . . . . . . . 15

2.2 Estabilidade Absoluta . . . . . . . . . . . . . . . . . . . 20

2.3 Condições Necessárias e Suficientes para Estabilidade Absoluta . . . . . . . . . . . . . 23

3 O Problema de Lurie e as Redes Neurais de Hopfield 29

3.1 O Problema de Lurie com Múltiplos Controles . . . . . . . . . . . . . . . . . . . . 29

3.2 Conceitos Básicos de Redes Neurais Artificiais . . . . . . . . . . . . . . . . . . . . 34

3.3 Rede Neural de Hopfield . . . . . . . . . . . . . . . . . . . . . . . . . . 36

3.4 Estabilidade de Hopfield . . . . . . . . . . . . . . . . . . . . . . . . . . . . . . 39

3.5 Relacionando a Rede Neural de Hopfield com o Problema de Lurie . . . . . . . . . . 42

$\begin{array}{ll}\text { Referências Bibliográficas } & 51\end{array}$ 


\section{Lista de Figuras}

1.1 Noção geométrica de estabilidade em dimensão $2 \ldots \ldots$. . . . . . . . . . . 2

1.2 Noção geométrica de estabilidade assintótica em dimensão $2 \ldots \ldots$. . . . . . . . . 2

1.3 Noção geométrica de instabilidade em dimensão $2 \ldots \ldots$. . . . . . . . . . . . . . . 3

1.4 Interpretação geométrica da função de Lyapunov para dimensão $2 . \quad \ldots . \ldots .7$

1.5 Conjunto de pontos $\omega$-limite . . . . . . . . . . . . . . . . . . . . 9

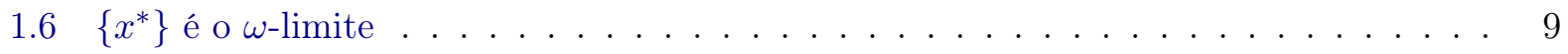

1.7 Plano de fase da equação unidimensional . . . . . . . . . . . . . . . . . . . . . . 10

1.8 Plano de fase da equação bidimensional . . . . . . . . . . . . . . . . . . . . . 10

2.1 Diagrama em blocos do sistema tipo Lurie . . . . . . . . . . . . . . . . . . 15

2.2 Tipos de funções $f:$ a) $F_{[0, k]}, F_{[0, k)}$; b) $F_{\left[k_{1}, k_{2}\right]}$; c) $F_{\infty} \ldots \ldots \ldots$

2.3 Os três eixos de rotação de uma aeronave . . . . . . . . . . . . . . . . . 17

2.4 Sistema de controle da aeronave . . . . . . . . . . . . . . . . . . . . 18

2.5 Sistema de controle da aeronave com controle do profundor . . . . . . . . . . 18

2.6 Governador centrifugo . . . . . . . . . . . . . . . . . . . . . . . . . . 19

3.1 Neurônio biológico . . . . . . . . . . . . . . . . . . . . . . . . 35

3.2 Neurônio artificial . . . . . . . . . . . . . . . . . . . . . . . 36

3.3 Operação do associador de padrão . . . . . . . . . . . . . . . . . . . 36

3.4 (a) realização da $\mathrm{RNH}$ (b) neurônio da $\mathrm{RNH} \ldots \ldots$. . . . . . . . . . . . . . 37

3.5 Representação de um nó no circuito de realização . . . . . . . . . . . . . . . . . . 38

3.6 (a) neurônio da RNH (b) RNH . . . . . . . . . . . . . . . . . . . . . . . 39

3.7 Plano de fase da RNH do exemplo (3.3) com os pontos de equilíbrio $u^{* 1}, u^{* 2}$ e $u^{* 1} \quad$. 47 


\section{Capítulo 1}

\section{Conceitos Preliminares}

Neste capítulo apresentaremos algumas definições e teoremas relevantes para o Problema de Lurie. Definiremos estabilidade no sentido de Lyapunov, funções de Lyapunov e demonstraremos um conhecido teorema sobre estabilidade para sistemas lineares. Em seguida enunciaremos e daremos uma demonstração do Princípio da Invariância de LaSalle. Por fim enunciaremos o Teorema de Barbashim-Krasovskii com a última parte devida a LaSalle, que é útil para o estudo da estabilidade de sistemas não lineares.

Na maior parte dos casos, estaremos trabalhando com o seguinte sistema autônomo de equações diferenciais ordinárias, conhecido como problema de valor inicial (PVI):

$$
\left\{\begin{array}{ccc}
\dot{x}(t) & = & f(x(t)) \\
x\left(t_{0}\right) & = & x_{0}
\end{array}\right.
$$

Onde $f: R^{n} \rightarrow R^{n}$, satisfaz condições que garantem que o problema 1.1 tenha solução única (que será denotada por $\left.x\left(t ; t_{0}, x_{0}\right)\right)$ definida em $\left[t_{0},+\infty\right)$. Considerando $f(0)=0$, e portanto $x(t)=0$ é a solução trivial.

\subsection{Estabilidade no Sentido de Lyapunov}

O que pode acontecer com a solução do sistema (1.1) com o passar do tempo? Será que a solução obtida se "aproxima" da solução trivial (ponto de equilíbrio)? ou será que o sistema "permanece" num estado próximo à solução trivial? Ou, ainda, será que a solução do sistema se "afasta" da solução trivial refletindo um desequilíbrio ao sistema?

O estudo dessas questões se originou com Lagrange e Dirichlet, foram, posteriormente, tratadas por Lyapunov e Poincaré, formando a Teoria da Estabilidade que nos leva à Teoria Geométrica de Equações Diferenciais Ordinárias. A compreensão das próximas definições é de extrema importância na Matemática Aplicada e ciências exatas em geral, sendo uma base fundamental para o estudo da teoria da estabilidade e controle. Esse trabalho permeia ao longo de todo seu conteúdo essas definições.

Para destacar a importância desse assunto podemos citar um exemplo clássico de um problema que talvez tenha colaborado para dar origem à Teoria da Estabilidade. O comportamento do Sistema Solar é estável ou poderá atingir uma situação crítica, provocada por pequenas perturbações que produzam seu desmembramento?

Para determinar o tipo de estabilidade da solução nula de (1.1) analisamos o comportamento das soluções em sua vizinhança. A seguir definiremos estabilidade, estabilidade assintótica e instabilidade para uma solução representada por um ponto de equilíbrio conhecido $x^{*}$.

Os pontos de equilíbrio são obtidos fazendo-se:

$$
f\left(x^{*}\right)=0 .
$$


Definição 1.1. Diremos que o ponto de equilíbrio $x^{*}$ de 1.1 é estável segundo Lyapunov se para todo $\epsilon>0$ existe $\delta>0$ tal que para todo $x_{0}$ com $\left|x_{0}-x^{*}\right|<\delta$ se verifica:

$$
\left|x\left(t ; t_{0}, x_{0}\right)-x^{*}\right| \leq \epsilon, \forall t \in\left[t_{0},+\infty\right)
$$

Isso significa que se existe uma bola de raio $\delta$ centrada em $x^{*}$ tal que, para qualquer trajetória $x\left(t ; t_{0}, x_{0}\right)$ com condição inicial $x_{0}$ pertencente a essa bola, então $x\left(t ; t_{0}, x_{0}\right)$ permanece dentro de uma outra bola de raio $\epsilon$ centrada em $x^{*}$ conforme o tempo passa.

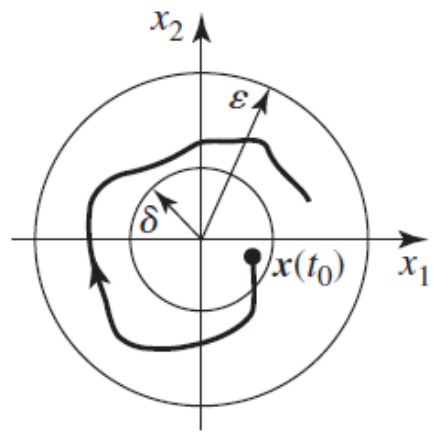

Figura 1.1: Noção geométrica de estabilidade em dimensão 2

Definição 1.2. Diremos que o ponto de equilíbrio $x^{*}$ de 1.1 é assintóticamente estável se é estável e existe $\eta>0$ tal que se $\left|x_{0}-x^{*}\right| \leq \eta$, então

$$
\lim _{t \rightarrow+\infty}\left|x\left(t ; t_{0}, x_{0}\right)\right|=x^{*} .
$$

Essa definição nos diz que $x^{*}$ será um ponto de equilíbrio assintoticamente estável se todas as trajetórias $x\left(t ; t_{0}, x_{0}\right)$, cujas condições iniciais estão contidas em uma bola de raio $\eta$ com centro em $x^{*}$, se aproximam de $x^{*}$ conforme o tempo passa.

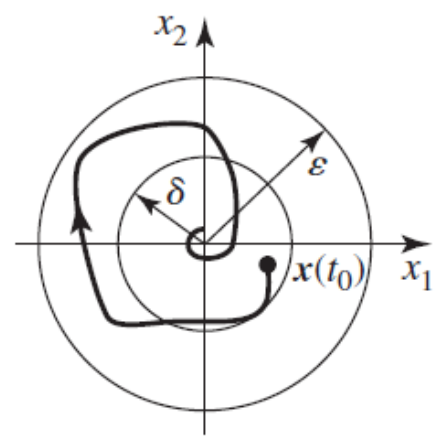

Figura 1.2: Noção geométrica de estabilidade assintótica em dimensão 2

Se essa bola possui raio finito, então $x^{*}$ é localmente assintoticamente estável, se tal bola possui raio infinito, então o ponto de equilíbrio é globalmente assintoticamente estável. Significando também que o ponto de equilíbrio precisa ser único.

Logo o ponto de equilíbrio que não é estável dizemos que o mesmo é instável, ou seja, se existe $x_{0}$ tal que, independente de quão próximo esteja de $x^{*}$, a trajetória correspondente se afasta da vizinhança de raio $\epsilon$ num tempo $t$ finito, então o ponto é instável.

Exemplo 1.1. O Pêndulo [4, 25, 31]. 


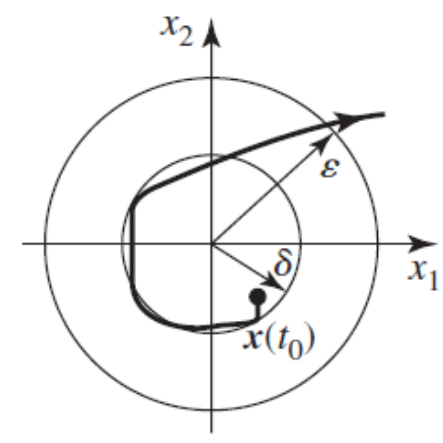

Figura 1.3: Noção geométrica de instabilidade em dimensão 2

O pendulo é um bom exemplo para exemplificar as definições de estabilidade enunciadas anteriormente. Considere a equação do pêndulo simples:

$$
l \ddot{\theta}+g \sin \theta=0
$$

tomando em forma de sistema, fazendo $\dot{\theta}=x$, obtemos

$$
\left\{\begin{array}{c}
\dot{\theta}=x \\
\dot{x}=-\frac{g}{l} \sin \theta
\end{array}\right.
$$

Onde l é o comprimento de uma barra ideal e $\theta$ é o ângulo da barra com a vertical.

Estabilidade Suponha que não exista nenhuma força atuando no pêndulo. Sendo livre de qualquer tipo de atrito ou amortecimento, então afastando-o ligeiramente do ponto de equilíbrio $\theta^{*}=0$, o pêndulo permanecerá oscilando em torno desse ponto de equilíbrio indefinidamente, ou seja, o ponto de equilíbrio $\theta^{*}=0$ é estável, pois nem se afasta nem se aproxima desse ponto.

Instabilidade. Estando agora o pêndulo invertido (de ponta cabeça), existe um novo ponto de equilíbrio $\theta^{* 1}=\pi$. Esse ponto é considerado instável, pois basta uma pequena perturbação para o pêndulo se afastar de tal ponto.

Estabilidade Assintótica. Considerando um amortecimento, equação (1.22), suponha que o pêndulo seja ligeiramente afastado do seu ponto de equilíbrio $\theta^{*}=0$, e em seguida solto. Observamos que sua oscilação diminui até retornar ao estado inicial, isto é, ao ponto de equilíbrio $\theta^{*}=0$. Portanto esse ponto de equilíbrio é assintoticamente estável, pois, a partir de qualquer condição inicial "próxima", a trajetória tende ao ponto de equilibrio $\theta^{*}=0$. Observemos que esse ponto é localmente assintoticamente estável já que nem todas trajetórias convergem para ele. De fato, se $\theta^{* 1}=\pi$ é a condição inicial do pêndulo, então permanece nessa condição conforme $t \rightarrow+\infty$.

\subsection{Estabilidade para Sistema Lineares}

Teremos a seguir um teorema que traz resultados sobre a estabilidade de soluções de um sistema linear de EDO. Esse teorema é provado utilizando conceitos de autovalores, autovetores, exponencial de matrizes, e forma de Jordan. A partir desse teorema conheceremos o conceito de matriz de Hurwitz e definiremos estabilidade exponencial, conceitos esses que são muito úteis no Problema de Lurie. 
Teorema 1.1. Consideremos o problema

$$
\begin{cases}\dot{x}(t) & =A x(t) \\ x\left(t_{0}\right) & =x_{0}\end{cases}
$$

sendo A uma matriz real $n \times n$ e seja $\lambda$ o autovalor de A com maior parte real., temos:

(a) Se $\mu<0$, é tal que Re $\lambda<\mu$, então a solução nula de 1.4 (ié, $x^{*}=0$ ) é assintoticamente estável.

(b) $S e \mu=0$ é tal que Re $\lambda=\mu$ e A diagonalizável em $C$, então a solução nula de 1.4(ié, $\left.x^{*}=0\right)$ é estável.

(c) $\quad$ Se $\mu>0$, é tal que Rè $>\mu$ então a solução nula de 1.4(ié, $\left.x^{*}=0\right)$ é instável.

Demonstração. (a) Seja $e^{A t}=P e^{J t} P^{-1}$ onde $J$ é a forma de Jordan da matriz $A$ tal que:

$$
e^{J t}=\left(\begin{array}{ccc}
e^{J_{1} t} & \cdots & 0 \\
\vdots & \ddots & \vdots \\
0 & \cdots & e^{J_{n} t}
\end{array}\right)
$$

sendo

$$
e^{J_{i} t}=e^{\lambda_{i} t}\left(\begin{array}{ccccc}
1 & 0 & 0 & \cdots & 0 \\
t / 1 ! & 1 & 0 & \cdots & 0 \\
t^{2} / 2 ! & t / 1 ! & 1 & \cdots & 0 \\
\vdots & \vdots & \vdots & \ddots & \\
t^{n-1} /(n-1) ! & t^{n-2} /(n-2) ! & t / 1 ! & \cdots & 1
\end{array}\right) .
$$

Para facilitar a notação considerando $t_{0}=0$, temos que $x\left(t ; 0, x_{0}\right)=x(t)=e^{A t} \cdot x_{0}$ é solução de 1.4, então por 1.5 e 1.6 os elementos de $e^{A t}$ são somas finitas de expressões do tipo $t^{i} e^{\lambda t}$, assim basta analisarmos um desses termos:

$$
\left|t^{i} e^{\lambda t} x_{0}\right| \leq|t|^{i} e^{(\operatorname{Re} \lambda) t}\left|x_{0}\right|=|t|^{i} e^{(\operatorname{Re} \lambda-\mu) t} e^{\mu t}\left|x_{0}\right|,
$$

como $\operatorname{Re} \lambda-\mu<0$, temos que $|t|^{i} e^{(\operatorname{Re} \lambda-\mu) t} \rightarrow 0$ quando $t \rightarrow+\infty$. Portanto $x(t) \rightarrow 0$ quando $t \rightarrow+\infty$ concluímos que a solução nula de 1.4 é assintoticamente estável. E ainda mais, existe uma constante $M$ tal que

$$
\|x(t)\| \leq M e^{\mu t}\left|x_{0}\right|
$$

(b) Se $\gamma$ é um autovalor de $A$ tal que $R e \gamma=0$, que é o mesmo que dizermos que $\gamma=\beta i$ com $\beta \in R$ e seja $x^{0}$ um autovetor correspondente a $\gamma$, ou seja, $A x^{0}=\beta i x^{0}$. Então $e^{A t} x^{0}=e^{\beta i t} x^{0}$ portanto, a solução $x(t)=e^{A t} \cdot x_{0}$ de 1.4 verifica $|x(t)|=\left|x^{0}\right|$, desse modo, não temos estabilidade assintótica.

(c) Seja $\gamma=\alpha+\beta i$ com $\alpha>0$ um autovalor de $A$, e seja $x^{0} \neq 0$ tal que $A x^{0}=(\alpha+\beta i) x^{0}$ então $x(t)=e^{a t} x^{0}=e^{(\alpha+\beta i) t} x^{0}$ e portanto $|x(t)|=e^{\alpha t}\left|x^{0}\right| \rightarrow \infty$ quando $t \rightarrow+\infty$.

Exemplo 1.2. Considere um sistema nas condições de (1.4), sendo A a seguinte matriz:

$$
A=\left(\begin{array}{cc}
-1 & 0 \\
0 & -2
\end{array}\right)
$$

Temos que a solução nula é assintoticamente estável, pois obtemos facilmente que o conjunto de autovalores de $A$ é (-1,-2), logo existe um $\mu<0$ tal que $-1<\mu$. 
Exemplo 1.3. Considere o sistema do pêndulo simples exposto na seção anterior, no entanto vamos considerar o caso das pequenas oscilações do pêndulo o que nos permite fazer uma aproximação $\sin \theta \cong \theta \operatorname{com} g=l$ :

$$
\left(\begin{array}{l}
\dot{x} \\
\dot{y}
\end{array}\right)=\left(\begin{array}{cc}
0 & 1 \\
-\frac{g}{l} & 0
\end{array}\right)\left(\begin{array}{l}
x \\
y
\end{array}\right)
$$

sendo $A=\left(\begin{array}{cc}0 & 1 \\ -\frac{g}{l} & 0\end{array}\right)$ a solução nula é estável, pois, como os autovalores de A são $(i,-i)$ e A é diagonalizável, temos $\mu=0$.

Exemplo 1.4. Para um sistema nas condições de (1.4) onde

$$
A=\left(\begin{array}{cccc}
2 & 1 & 0 & 0 \\
0 & 2 & 0 & 0 \\
0 & 0 & 1 & 1 \\
0 & 0 & 4 & -2
\end{array}\right)
$$

o polinômio característico: $p(\lambda)=(2-\lambda)^{3}(-3-\lambda)$.

Temos que o conjunto de autovalores de A é (2,-3), logo existe um $\mu>0$ tal que $2>\mu$, portanto, conforme o teorema, o sistema é instável.

Para esse trabalho serão úteis as seguintes definições:

Definição 1.3. Uma matriz é de Hurwitz se todos os autovalores têm parte real negativa.

Conforme o teorema anterior, se $A$ é a matriz de coeficientes de um sistema linear e $A$ é de Hurwitz, então tal sistema possui solução nula assintoticamente estável.

Definição 1.4. Dizemos que a solução nula do sistema 1.4 é exponencialmente assintoticamente estável se existe $\mu>0$ maior que a parte real de todos autovalores de A, satisfazendo

$$
|| x(t) \| \leq M e^{-\mu t}\left|x_{0}\right|
$$

onde $M$ é uma constante.

Isso quer dizer, de um ponto de visto local, que uma solução próxima ao ponto de equilíbrio com condição inicial $x_{0}$ converge para o ponto de equilíbrio com uma taxa mais rápida do que alguma função exponencial. Se o ponto de equilíbrio é único temos a definição sob um ponto de vista global.

\subsection{Funções de Lyapunov}

O matemático russo Aleksandr Mikhailovich Lyapunov por volta de 1892 elaborou um método, conhecido por Método Direto de Lyapunov, cuja proposta é analisar a estabilidade de uma solução de equilíbrio usando certas funções, conhecidas hoje como funções de Lyapunov. A construção de uma função de Lyapunov geralmente não segue um método universalmente válido, o que temos em mãos são algumas regras e principalmente a experiência para a obtenção dessa função. A seguir temos a definição da função de Lyapunov, extraída de [4], que se encaixa ao nosso problema inicial 1.1 , isto é: $\dot{x}(t)=f(x(t))$, onde $f: R^{n} \rightarrow R^{n}$, satisfaz condições que garantem que o problema:

$$
\left\{\begin{array}{ccc}
\dot{x}(t) & = & f(x(t)) \\
x\left(t_{0}\right) & = & x_{0}
\end{array}\right.
$$


tenha solução única (que será denotada por $\left.x\left(t ; t_{0}, x_{0}\right)\right)$ definida em $\left[t_{0},+\infty\right)$. Considerando o ponto de equilíbrio $x^{*}=0$, e portanto $x(t)=0$ é solução.

Definição 1.5. Seja $V: \Omega \subset R^{n} \rightarrow R$ uma função de classe $C^{1}$, definida num conjunto $\Omega$ que contém uma bola fechada com centro na origem. Dizemos que $V$ é uma função de Lyapunov para a equação 1.1 quando:

1) $V(0)=0, V(x)>0$, se $x \neq 0$;

2) $\frac{d V}{d t}(x) \leq 0$, para todo $x$.

$$
\text { onde } \frac{d V}{d t}: \Omega \rightarrow R \text { é definida por: } \frac{d V}{d t}(x(t))=\langle\nabla V(x), f(x)\rangle
$$

Além disso, dizemos que $V$ é uma função de Lyapunov estrita, quando $\dot{V}(x)<0$, para $x \neq 0$.

Exemplo 1.5. Obter uma função de Lyapunov para o seguinte sistema:

$$
\left\{\begin{array}{l}
x^{\prime}(t)=a(x(t))^{3}+b y(t) \\
y^{\prime}(t)=-c x(t)+d(y(t))^{3}
\end{array}\right.
$$

Para facilitar as notações, a partir de agora, onde se lê $(x, y)$ entenda-se por $(x(t), y(t))$.

Seja $(x, y)$ solução e utilizando o método de equações separáveis, procuramos um equação da forma

$$
V(x, y)=V_{1}(x)+V_{2}(y)
$$

partindo da condição 2 da definição 1.5, para termos (1.9) não crescente é suficiente que

$$
\frac{d V}{d t}=\frac{\partial V_{1}}{\partial x} \frac{d x}{d t}+\frac{\partial V_{2}}{\partial y} \frac{d y}{d t} \leq 0
$$

$\log$,

$$
\begin{gathered}
\frac{d V}{d t}=\frac{\partial V_{1}}{\partial x}\left(a x^{3}+b y\right)+\frac{\partial V_{2}}{\partial y}\left(-c x+d y^{3}\right) \\
\frac{d V}{d t}=\frac{\partial V_{1}}{\partial x}\left(a x^{3}\right)+\frac{\partial V_{1}}{\partial x}(b y)+\frac{\partial V_{2}}{\partial y}(-c x)+\frac{\partial V_{2}}{\partial y}\left(d y^{3}\right) .
\end{gathered}
$$

Se

$$
\frac{\partial V_{1}}{\partial y}(b y)+\frac{\partial V_{2}}{\partial y}(-c x)=0,
$$

teremos chances de obter a condição (1.10).

Para que (1.12) aconteça é suficiente que:

$$
\begin{gathered}
\frac{\partial V_{1}}{\partial y}=(c x) e \frac{\partial V_{2}}{\partial y}=(b y) \\
V_{1}=\int(c x) d x=\frac{c x^{2}}{2} \quad \text { e } \quad V_{2}=\int(b y) d x=\frac{b y^{2}}{2},
\end{gathered}
$$

portanto,

$$
V=\frac{c x^{2}}{2}+\frac{b y^{2}}{2} .
$$


Que satisfaz a condição 1 da definição 5 se $c>0$ e b $>0$ ou $c<0$ e $b<0$, nesse caso, $V=-\left(\frac{c x^{2}}{2}+\frac{b y^{2}}{2}\right)$ portanto:

$$
b c>0 .
$$

Para verificarmos a condição 2 do teorema basta substituirmos (1.13) em (1.11):

$$
\frac{d V}{d t}=c x a x^{3}+c x b y-b y c x+b y d y^{3}=a c x^{4}+b d y^{4},
$$

com isso, para satisfazer (1.10) temos que fazer:

$$
a c \leq 0 \quad e \quad b d \leq 0 .
$$

Portanto, se valem as condições (1.16) e (1.17) V é uma função de Lyapunov para a equação (1.1).

Além disso se

$$
a c<0 \quad e \quad b d<0 .
$$

então teremos:

$$
\frac{d V}{d t}=\frac{\partial V}{\partial x} \frac{d x}{d t}+\frac{\partial V}{\partial y} \frac{d y}{d t}<0 .
$$

Assim $V$ é uma função de Lyapunov estrita para o problema (1.8).

Teremos garantida a estabilidade do ponto de equilíbrio se obtemos uma função de Lyapunov semi-definida negativa, isto é, $\frac{d V}{d t}(x) \leq 0$ (fig 1.4a). É provado que se obtemos uma função de Lyapunov estrita, ou seja, $\frac{d V}{d t}<0$, então é garantida a estabilidade assintótica do ponto de equilíbrio (fig. 1.4b).
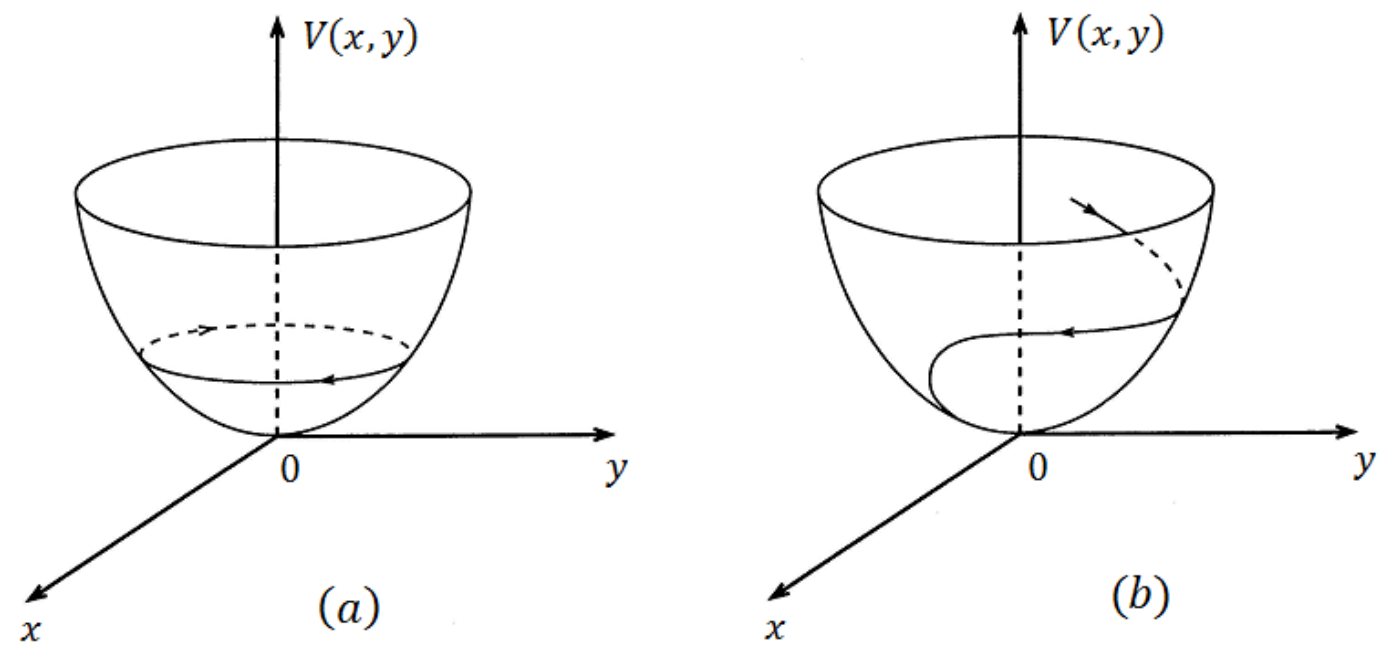

Figura 1.4: Interpretação geométrica da função de Lyapunov para dimensão 2.

\subsection{Um Pouco Mais Sobre o Método Direto de Lyapunov}

Agora temos um método útil para se obter funções de Lyapunov para sistemas lineares com coeficientes constantes, o qual para o problema de Lurie será importante para a obtenção da Função Lyapunov-Lurie. 
Considere o problema linear com coeficientes constantes como dado pela equação (1.4), então desejamos construir uma função tal que

$$
V(x)=\langle B x, x\rangle,
$$

onde $\mathrm{B}$ é uma matriz real simétrica $n \times n$. A matriz B pode ser obtida resolvendo a seguinte equação:

$$
A^{T} B+B A=-C,
$$

sendo $A \in R^{n x n}$ matriz de coeficientes do sistema linear de EDO (1.4).

Suponha $C$ é uma matriz simétrica definida positiva, isto é, $\langle C x, x\rangle>0$. Satisfeitas essas condições e resolvida a equação (1.20) obtemos a função de Lyapunov, pois

$$
\frac{d V(x)}{d t}=-\langle C x, x\rangle
$$

Assim temos que todos os coeficientes da matriz $A$ de (1.4) possuem parte real negativa, logo o sistema é assintoticamente estável.

Exemplo 1.6. Obtenha uma função de Lyapunov para o seguinte sistema [38]:

$$
\begin{aligned}
\left\{\begin{aligned}
\dot{x}_{1} & =x_{2} \\
\dot{x}_{2} & =-x_{1}+-2 x_{2}
\end{aligned}\right. \\
A=\left(\begin{array}{cc}
0 & 1 \\
-1 & -2
\end{array}\right) .
\end{aligned}
$$

Vamos resolver a equação $A^{T} B+B A=-C$, assumindo que $C=I_{2}$ e $B$ assume a forma:

$$
B=\left(\begin{array}{ll}
b_{1} & b_{2} \\
b_{2} & b_{4}
\end{array}\right)=B^{T}
$$

Temos

$$
\begin{gathered}
A^{T} B+B A=\left(\begin{array}{ll}
b_{1} & b_{2} \\
b_{2} & b_{4}
\end{array}\right)\left(\begin{array}{cc}
0 & -1 \\
1 & -2
\end{array}\right)+\left(\begin{array}{ll}
b_{1} & b_{2} \\
b_{2} & b_{4}
\end{array}\right)\left(\begin{array}{cc}
0 & 1 \\
-1 & -2
\end{array}\right) \\
=\left(\begin{array}{cc}
-2 b_{1} & -b_{3}+b_{1}-2 b_{2} \\
-b_{3}+b_{1}-2 b_{2} & 2 b_{2}-4 b_{3}
\end{array}\right)=-\left(\begin{array}{ll}
1 & 0 \\
0 & 1
\end{array}\right),
\end{gathered}
$$

resolvendo a equação anterior:

$$
B=\left(\begin{array}{cc}
3 / 2 & 1 / 2 \\
1 / 2 & 1 / 2
\end{array}\right)
$$

Como $B=B^{T}$ então

$$
V(x)=\langle B x, x\rangle,
$$

é uma função de Lyapunov para o sistema. Isso implica que a solução trivial do sistema é assintoticamente estável, pois é fácil verificar que:

$$
\frac{d V(x)}{d t}=-\langle C x, x\rangle .
$$

\subsection{O Princípio da Invariância de LaSalle}

$\mathrm{Na}$ teoria de Estabilidade o estudo do comportamento assintótico de soluções de equações diferenciais certamente é o centro das expectativas de todo cientista, porém nunca foi uma tarefa fácil, principalmente quando se trata de equações não lineares. Trata-se do estudo dessas soluções quando tendem a algum ponto, no nosso caso, o ponto de equilíbrio. O comportamento assintótico 
da solução é determinado pelo conhecimento de seu conjunto $\omega$-limite, no entanto a determinação desse conjunto geralmente é bastante complicada. LaSalle em 1960 [14] obteve resultados significativos sobre o comportamento assintótico de soluções via estudo do conjunto $\omega$-limite, sendo hoje, o Princípio da Invariância de LaSalle uma das principais ferramentas para estudar o comportamento assintótico de soluções de equações diferenciais. A informação é obtida utilizando uma função $V$ que geralmente são funções de Lyapunov.

Definição 1.6. O conjunto $\gamma\left(x_{0}\right)=\left\{x\left(t, t_{0} ; x_{0}\right), t \geq t_{0}\right\}$ é chamado de semi-trajetória positiva de (1.1) através de $x_{0}$.

Definição 1.7. O conjunto $\omega(\gamma)=\omega\left(x_{0}\right)=\left\{x \in R^{n}: \exists t_{n} \rightarrow+\infty \quad \mid \quad x=\lim _{t_{n} \rightarrow+\infty} x\left(t_{n}, t_{0} ; x_{0}\right)\right\}$ é chamado de conjunto $\omega$-limite da semi-trajetória $\gamma$ que passa por $x_{0}$.

Podemos entender o conjunto $\omega$-limite como sendo aquele onde "chega"a semi-trajetória $\gamma$ a partir da condição inicial $x_{0}$ (fig. 1.5).

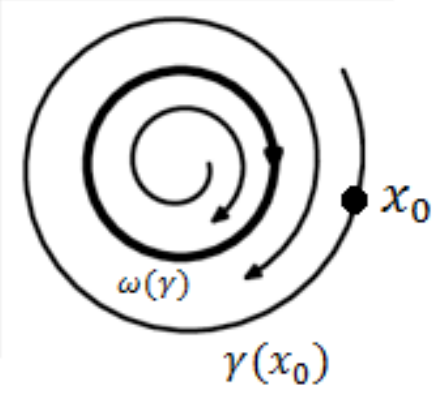

Figura 1.5: Conjunto de pontos $\omega$-limite

Por outro lado as vezes acontece que um ponto de equilíbrio $x^{*}$ é o conjunto $\omega$-limite, nesse caso deveremos ter $x^{*}=\lim _{t_{n} \rightarrow+\infty} x\left(t_{n}, t_{0} ; x_{0}\right)$. Logo $w(\gamma)=\left\{x^{*}\right\}$ (fig. 1.6).

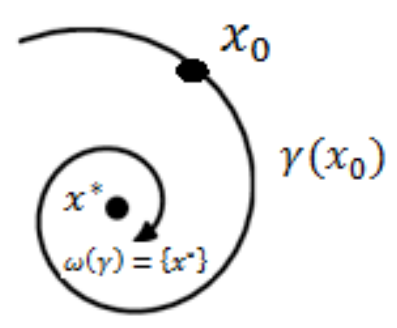

Figura 1.6: $\left\{x^{*}\right\}$ é o w-limite

\section{Exemplo 1.7. Caso unidimensional.}

Considere a seguinte equação diferencial:

$$
\dot{x}=x(1-x) .
$$

Os pontos de equilíbnrio dessa equação são $x_{1}^{*}=0$ e $x_{2}^{*}=1$, observando o plano de fase (fig. 1.7), e verificando os pontos w-limite, temos:

$$
\begin{aligned}
& w\left(x_{0}\right)=\{1\} \text { para } x_{0}>0 . \\
& w(0)=\{0\} \text { e } w\left(x_{0}\right)=\{\} \text { para } x_{0}<0 .
\end{aligned}
$$

\section{Exemplo 1.8. Caso bidimensional.}




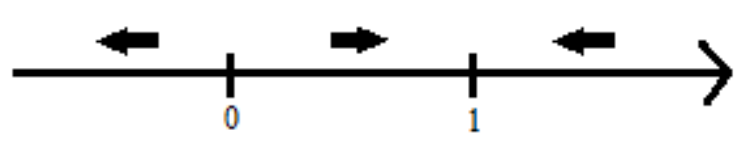

Figura 1.7: Plano de fase da equação unidimensional

Considere o seguinte sistema de equação diferencial:

$$
\begin{cases}\dot{x_{1}} & =x_{1} \\ \dot{x_{2}} & =-x_{2}\end{cases}
$$

O ponto de equilíbrio dessa equação é $\left(x_{1}^{*}, x_{2}^{*}\right)=(0,0)$, observando o plano de fase (fig. 1.8), e verificando os pontos w-limite, temos:

$$
\begin{aligned}
& w\left(x_{0}\right)=\{\quad\} \text { se } x_{0} \in \text { eixo } x_{1} \text { e } x_{0} \neq 0 \\
& w\left(x_{0}\right)=\{0\} \text { se } x_{0} \in \text { eixo } x_{2}
\end{aligned}
$$

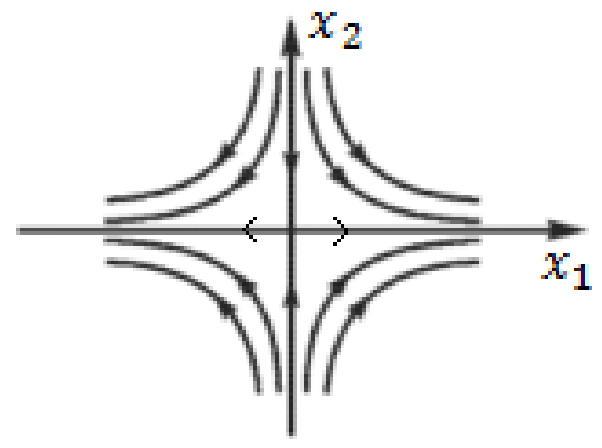

Figura 1.8: Plano de fase da equação bidimensional

O teorema a seguir enuncia o Princípio da Invariânica de LaSalle e é útil para encontrar conjuntos $\omega$-limite em sistemas não lineares, pois o mesmo conclui que satisfeitas as hipóteses então toda a solução limitada de (1.1) converge para o maior conjunto invariante $\omega\left(x_{0}\right)$ possibilitando saber se de fato $x^{*}$ é ponto $\omega$-limite de (1.1).

Teorema 1.2. Se $V: R^{n} \rightarrow R$ é de classe $C^{1}$ tal que $\frac{d V}{d t}(x(t)) \leq 0$. Então

$$
\omega\left(x_{0}\right) \subset E=\left\{x \in R^{n}: \frac{d V}{d t}(x(t))=0\right\}
$$

para todo $x_{0} \in R^{n}$.

Demonstração. Basta considerar o caso em que $\omega\left(x_{0}\right) \neq\{\}$. Nesse caso, temos que $V(t)=$ $V\left(x\left(t, x_{0}\right)\right)$ é decrescente, pois $\dot{V} \leq 0 . V(t)$ é limitada inferiormente. De fato, se $y \in \omega\left(x_{0}\right)$, existem $t_{n} \rightarrow \infty$ tais que $x\left(t_{n}, x_{0}\right) \rightarrow y$. Portanto, pela continuidade de $V$, temos que $V\left(t_{n}\right) \rightarrow V(y)$. Pela monotonicidade de $V$, temos que $V(t) \rightarrow c=V(y)$, quando $t \rightarrow \infty$. Mostramos assim que $V$ é constante igual a $c$ em $\omega\left(x_{0}\right)$. Agora como o conjunto $\omega$-limite é invariante, isto é, se $y \in \omega\left(x_{0}\right)$, então $x(t, y) \in \omega\left(x_{0}\right)$ para todo $t$, segue-se que $V(x(t, y))=c$. Logo $\dot{V}=0$, isto é, $y \in E$, que prova o teorema. 
Exemplo 1.9. Considere a equação do pêndulo, parecido ao exemplo 1 da seção 1.1, porém, agora com um amortecimento. Tomando agora $\theta=x_{1}$ e $x=x_{2}$ temos o seguinte sistema

$$
\left\{\begin{array}{lc}
\dot{x_{1}}= & x_{2} \\
\dot{x_{2}}= & -\frac{g}{l} \sin x_{1}-\frac{k}{m} x_{2}
\end{array}\right.
$$

queremos obter informações a respeito das soluções $x\left(t ; t_{0}, x_{0}\right)$.

Utilizando inicialmente como candidata a seguinte função:

$$
V(x)=\frac{g}{l}\left(1-\cos x_{1}\right)+\frac{1}{2} x_{2}^{2}
$$

temos:

$$
\dot{V}(x)=\frac{g}{l} \dot{x_{1}}\left(\sin x_{1}\right)+x_{2} \dot{x_{2}}
$$

substituindo $\dot{x}_{1}$ e $\dot{x}_{2}$ obtemos:

$$
\dot{V}(x)=-\frac{k}{m} x_{2}^{2}
$$

portanto $\dot{V}(x) \leq 0$. Não podemos afirmar que $\dot{V}$ é estritamente negativa pois não conhecemos $x_{1}$. $O$ conjunto $E$ é dado por: $E=\left\{\left(x_{1}, X_{2}\right) \in R^{2}: \frac{d V}{d t}(x(t))=0\right\}$, então:

$$
\dot{V}(x)=0 \Rightarrow-\frac{k}{m} x_{2}^{2}=0 \Rightarrow x_{2}=0
$$

Portanto $E=\left\{\left(x_{1}, x_{2}\right) \in R^{2}: x_{2}=0\right\}$ no entanto ainda não conhecemos $x_{1}$. Para isso suponhamos $x(t)$ sendo uma trajetória que pertence identicamente ao conjunto $E$, de fato pois como o conjunto $\omega$-limite é invariante, isto é, se $y \in w\left(x_{0}\right)$ então $x(t, y) \in w\left(x_{0}\right)$, para todo $t$. Então tomando o problema (1.22), temos:

$$
x_{2}(t)=0 \Rightarrow \dot{x}_{2}=0 \rightarrow \frac{g}{l} \sin \left(x_{1}(t)\right)=0 \Rightarrow x_{1}(t)=0
$$

Então a única solução que pode permanecer em E é a solução trivial, $x(t)=0$, ou seja, $x^{*}=0$, portanto o conjunto $\omega$-limite de qualquer solução é o conjunto $\{0,0\}$.

Existe ainda uma versão extendida do Princípio da Invariância de LaSalle proposto e demonstrado pela primeira vez por Rodrigues, Alberto e Bretas em 1998 [33], que propõe a utilização de funções não somente de Lyapunov como definimos neste trabalho, mas funções que nem sempre são semi-definidas negativas.

\subsection{Estabilidade para Sistemas Não Lineares}

O Princípio da Invariância de LaSalle, embora não mencione estabilidade, sabemos que é uma ferramenta importante para o estudo do comportamento assintótico de uma solução por meio de seu conjunto ômega-limite como vimos na seção anterior. Utilizando essa idéia Guzman [7] apresenta um importante teorema sobre estabilidade assintótica global, sendo a sua primeira parte devida a Barbashin-Krasoviskii [2] e a segunda parte é um complemento devido a LaSalle [15].

Teorema 1.3. Considerando o problema (1.1), temos o seguinte:

1) Se $x(t)$ é uma solução qualquer distinta da trivial, e $V(x(t))$ é uma função de Lyapunov tal que,

$$
\frac{d V(x(t))}{d t}(t)<0 \quad \forall t
$$


Então, a solução trivial é globlamente assintoticamente estável, ou seja, sendo $x(t)$ uma solução qualquer então:

$$
\lim _{t \rightarrow \infty} x(t)=0 .
$$

Podemos, em lugar da condição 1), verificar a seguinte condição:

2) Se a função de Lyapunov não é estrita, isto é,

$$
\frac{d V(x(t))}{d t} \leq 0
$$

e o conjunto

$$
M=\left\{\xi \in R^{n}: \frac{d V(\xi)}{d \xi}=0\right\},
$$

contiver apenas a solução trivial $x(t)=0$, então a conclusão de 1) também á válida.

Exemplo 1.10. No exemplo da seção anterior temos que a única solução que pode permanecer em $E \equiv M$ é a solução trivial $x(t)=0$ portanto o sistema é globalmente assintoticamente estável.

Vamos encerrar esse capítulo com um exemplo que pode ser considerado um caso particular do Problema de Lurie, o Problema de Aizermam ou também conhecido como a Conjectura de Aizerman. Em 1947 Aizerman [1] propõe em sua surpreendente conjectura a idéia de se estudar estabilidade de uma classe de sistemas não lineares apenas pelo estudo da estabilidade de sistemas lineares, iniciando assim pelos pesquisadores da época uma grande corrida na tentativa de validação da teoria. Logo, em 1953 Krasovskii [11] provou que de fato a conjectura era válida para sistemas de dimensão 2 e para alguns sistemas de dimensões superiores, criando a expectativa que talvez ela fosse sempre válida. Porém, em 1958, Pliss [27] apresentou um contraexemplo em dimensão 3 invalidando a conjectura inicial de Aizerman. O Problema de Aizerman deixou importantes contribuições para o estudo da estabilidade de sistemas de controle não linear e para a teoria da estabilidade absoluta de sistemas de controle tipo Lurie, no entanto atualmente poucos pesquisadores se voltam para esse problema. O Problema de Aizerman pode ser estudado de forma mais detalhada em [31].

A solução do problema para dimensão 2 é uma aplicação direta do teorema 1.3., como temos a seguir.

\section{Exemplo 1.11. (O Problema de Aizerman em dimensão 2 [31])}

Considere o problema que apresenta uma não lineariade $f\left(x_{1}\right)$ onde no caso linear teríamos $a x_{1}(t)$ sendo $a \in R$ :

$$
\left\{\begin{array}{l}
\dot{x}_{1}(t)=f\left(x_{1}(t)\right)+b x_{2}(t) \\
\dot{x}_{2}(t)=c x_{1}(t)+d x_{2}(t)
\end{array}\right.
$$

onde $f: R \rightarrow R$ é contínua e $f(0)=0$.

\section{Para que condições o Problema (1.28) é globalmente assintoticamente estável}

A resolução desse problema consiste em encontrar uma função que satisfaça as condições do teorema 1.3. Então, considere a função: 


$$
\begin{gathered}
V\left(\xi_{1}, \xi_{2}\right)=\int_{0}^{\xi_{1}}(f(s) d-b c s) d s+\frac{1}{2}\left(d \xi_{1}-b \xi_{2}\right)^{2} \quad \text { se } \quad \xi_{1} \geq 0 \\
\text { ou } \\
V\left(\xi_{1}, \xi_{2}\right)=-\int_{\xi_{1}}^{0}(f(s) d-b c s) d s+\frac{1}{2}\left(d \xi_{1}-b \xi_{2}\right)^{2} \quad \text { se } \quad \xi_{1}<0 .
\end{gathered}
$$

Para facilitar as notações, onde se lê $\left(x_{1}, x_{2}\right)$ entenda-se por $\left(x_{1}(t), x_{2}(t)\right)$ e $x(t)=\left(x_{1}(t), x_{2}(t)\right)$. Então:

$$
\begin{gathered}
\frac{d V(x(t))}{d t}=\frac{\partial V}{\partial x_{1}} \frac{d x_{1}}{d t}+\frac{\partial V}{\partial x_{2}} \frac{d x_{2}}{d t}, \\
\frac{d V(x(t))}{d t}=\left(f\left(x_{1}\right) d-b c x_{1}\right) \dot{x}_{1}+\left(d x_{1}-b x_{2}\right)\left(d \dot{x}_{1}-b \dot{x}_{2}\right), \\
\frac{d V(x(t))}{d t}=(f(x) d-b c x)(f(x)+b y)+(d x-b y)(d(f(x)+b y)-b(c x+d y)),
\end{gathered}
$$

$\log$,

$\frac{d V(x(t))}{d t}=d f\left(x_{1}\right)^{2}-b c x_{1} f\left(x_{1}\right)+d^{2} x_{1} f\left(x_{1}\right)-b c d x_{1}^{2}=d f\left(x_{1}\right)\left(f\left(x_{1}\right)+d x_{1}\right)-b c x_{1}\left(f\left(x_{1}\right)+d x_{1}\right)$, e finalmente,

$$
\frac{d V(x(t))}{d t}=\left(f\left(x_{1}\right)+d x_{1}\right)\left(d f\left(x_{1}\right)-b c x_{1}\right) .
$$

Se adotarmos

$$
f\left(x_{1}\right)+d x_{1}<0 \quad e \quad d f\left(x_{1}\right)-b c x_{1}>0,
$$

concluímos que

$$
\frac{d V(x(t))}{d t} \leq 0
$$

Como a equação (1.30) só depende de $x_{1}$, é possível garantir apenas que $\frac{d V(x(t))}{d t} \leq 0$, logo não é possivel garantir pela condição 1) do teorema 1.3. que o sistema é globalmente assintoticamente estável. Aplicando, agora, a condição 2) observamos que para $\frac{d V(x(t))}{d t}=0 \mathrm{em}$ (1.30) devemos ter $x_{1}=0$. Note que o conjunto $M$ é o conjunto de todos os pontos da solução $\left(x_{1}, x_{2}\right)$ onde $\frac{d V(x(t))}{d t}=0$. Considerando a solução $\left(0, x_{2}\right)$ verificamos junto a (1.26) se existe alguma solução além da trivial no conjunto $M$ :

$$
\left\{\begin{array}{l}
x_{1}^{\prime}(t)=f\left(x_{1}(t)\right)+b x_{2}(t) \\
x_{2}^{\prime}(t)=c x_{1}(t)+d x_{2}(t)
\end{array} \Rightarrow 0=f(0)+b x_{2}(t) \Rightarrow x_{2}(t)=0 .\right.
$$

Portanto, o conjunto $M$ é composto somente da solução trivial, então para todo $t$ e pelas condições impostas em (1.31) a solução trivial de (1.28), ou seja, o ponto de equilíbrio $x^{*}=0$ é globalmente assintoticamente estável. 


\section{Capítulo 2}

\section{O Problema de Lurie}

Anatoly Isakovich Lurie (19 de julho de 1901 - 12 de fevereiro de 1980) nasceu em Mogilev (Belorussia), trabalhou no campo da mecânica e teoria de controle, deixando um grande legado [42]. Em 1944 Lurie imbuído em resolver um problema de estabilidade do sistema de controle automático de uma aeronave propôs um sistema de equações diferenciais ordinárias. A partir desse sistema e da análise da estabilidade da solução nula do sistema, isto é, o ponto de equilíbrio, podia-se obter um controle, buscando condições necessárias e suficientes para estabilidade assintótica global do referido sistema.

Nesse capítulo vamos apresentar o Problema de Lurie, onde iniciaremos, na primeira seção, conhecendo de fato o famoso Sistema de Controle Tipo Lurie com alguns exemplos a fim de facilitar a compreensão.

Em sequência definiremos o conceito de Estabilidade Absoluta, que surge a partir de sistemas tipo Lurie. Dois teoremas serão apresentados, o primeiro devido ao próprio Lurie, que foi, talvez o primeiro teorema sobre estabilidade absoluta, e um outro teorema devido a Xie [35] (extraído de [18]), que se mostrou muito útil para a determinação das condições para estabilidade absoluta.

E como última seção deste capítulo, com finalidade didática, apresentaremos um teorema, que em partes é devido a Guzman [7], a fim de que o leitor possa se familiarizar com a teoria de Lurie para futuras pesquisas, trazendo resultados do contexto da época do inicio da teoria. Encerraremos esse capítulo trazendo condições necessárias e suficientes para casos de ordem 2, 3 e n, visualizando assim como tem sido generalizado o Problema de Lurie para um único controle.

\subsection{Sistema de Controle Tipo Lurie}

O Sistema de Controle Tipo Lurie, ou resumidamente, sistema tipo Lurie, é um sistema de EDO, sendo em sua forma mais simples um sistema autônomo.

Seja o seguinte diagrama em blocos, que representa um problema de controle não linear:

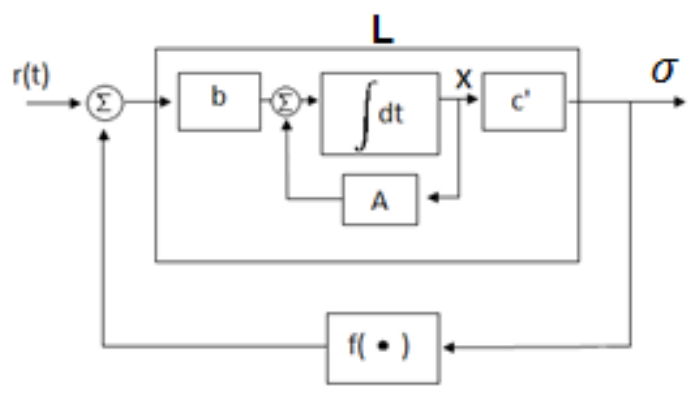

Figura 2.1: Diagrama em blocos do sistema tipo Lurie

Considerando a entrada $r(t)$ nula, o diagrama acima é expressado pelo seguinte sistema de 
equações diferenciais, com uma saída:

$$
\left\{\begin{array}{l}
\dot{x}=A x+b f(\sigma) \\
\sigma=c^{\prime} x
\end{array}\right.
$$

onde $x \in R^{n}, b, c \in R^{n}, A \in R^{n x n}$ e $\sigma f(\sigma)>0$.

O sistema tipo Lurie na literatura tem sido classificado em três tipos:

1) Sistema de controle direto, quando a matriz $A$ é Hurwitz.

2) Sistema de controle indireto, quando a matriz $A$ tem um autovalor com parte real zero e os demais com parte real negativa.

3) Sistema de controle crítico quando não temos nenhum autovalor da matriz $A$ com parte real positiva.

Um ponto bastante interessante no sistema tipo Lurie é a função $f$. Essa função é uma não linearidade restrita ao $1^{\circ}$ e $3^{\circ}$ quadrantes do plano $(\sigma, f)$. Sua forma não é especificada, mas sabe-se que ela pertence a algum tipo de função $F_{[0, k]}, F_{[0, k)}, F_{[0, k]}, F_{\left[k_{1}, k_{2}\right]}$ ou $F_{\infty}$, todas contínuas, que são definidas como:

$$
\begin{gathered}
F_{[0, k]}:=\left\{f \mid f(0)=0,0<\sigma f(\sigma) \leq k \sigma^{2}, \sigma \neq 0\right\}, \\
F_{[0, k)}:=\left\{f \mid f(0)=0,0<\sigma f(\sigma)<k \sigma^{2}, \sigma \neq 0\right\}, \\
F_{\left[k_{1}, k_{2}\right]}:=\left\{f \mid f(0)=0, k_{1} \sigma^{2} \leq \sigma f(\sigma) \leq k_{2} \sigma^{2}, \sigma \neq 0\right\}, \\
F_{\infty}:=\{f \mid f(0)=0, \sigma f(\sigma)>0, \sigma \neq 0\} .
\end{gathered}
$$

Graficamente essas funções são representadas da seguinte forma:

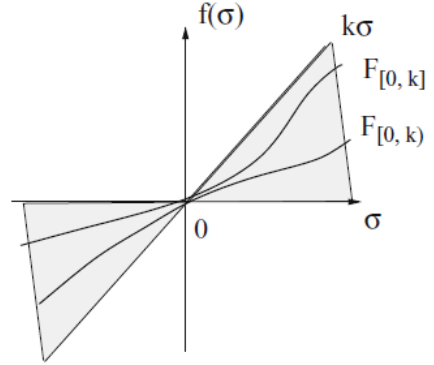

(a)

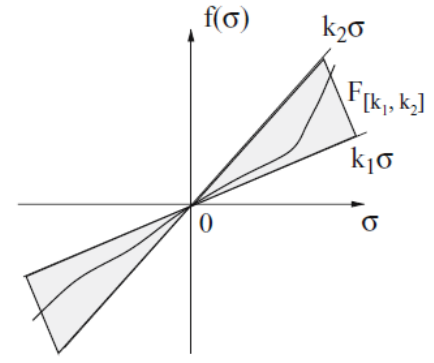

(b)

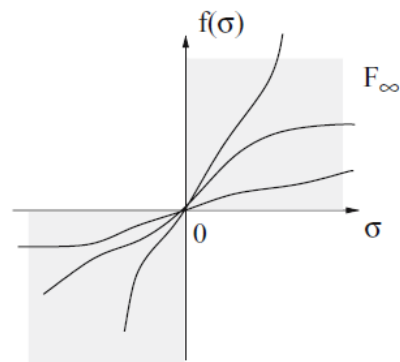

(c)

Figura 2.2: Tipos de funções $f:$ a) $F_{[0, k]}, F_{[0, k)}$; b) $F_{\left[k_{1}, k_{2}\right]}$; c) $F_{\infty}$ 


\section{Exemplo 2.1. (O Problema de Aizerman)}

O Problema de Aizerman visto no capítulo anterior é um caso particular de um sistema tipo Lurie:

$$
\left\{\begin{array}{l}
\dot{x_{1}}=f\left(x_{1}\right)+b_{1} x_{2} \\
\dot{x_{2}}=c_{1} x_{1}+d x_{2}
\end{array}\right.
$$

Nesse caso:

$$
x=\left(\begin{array}{l}
x_{1} \\
x_{2}
\end{array}\right), A=\left(\begin{array}{cc}
0 & b_{1} \\
c_{1} & d
\end{array}\right), b=\left(\begin{array}{l}
1 \\
0
\end{array}\right), c^{\prime}=\left(\begin{array}{ll}
1 & 0
\end{array}\right) .
$$

\section{Exemplo 2.2. (Sistema de Controle Automático de Aeronaves [24, 32])}

Como vimos na introdução do capítulo, o Problema de Lurie se originou justamente com um problema desse tipo. As aeronaves de asa fixa possuem suas superfícies móveis, os profundores, ailerons, e leme. Os profundores são responsáveis pelos movimentos de subida ou descida da aeronave (pitch), os ailerons pela rolagem (roll), e os lemes pelos movimentos de direção (yaw) da aeronave, figura 2.3.

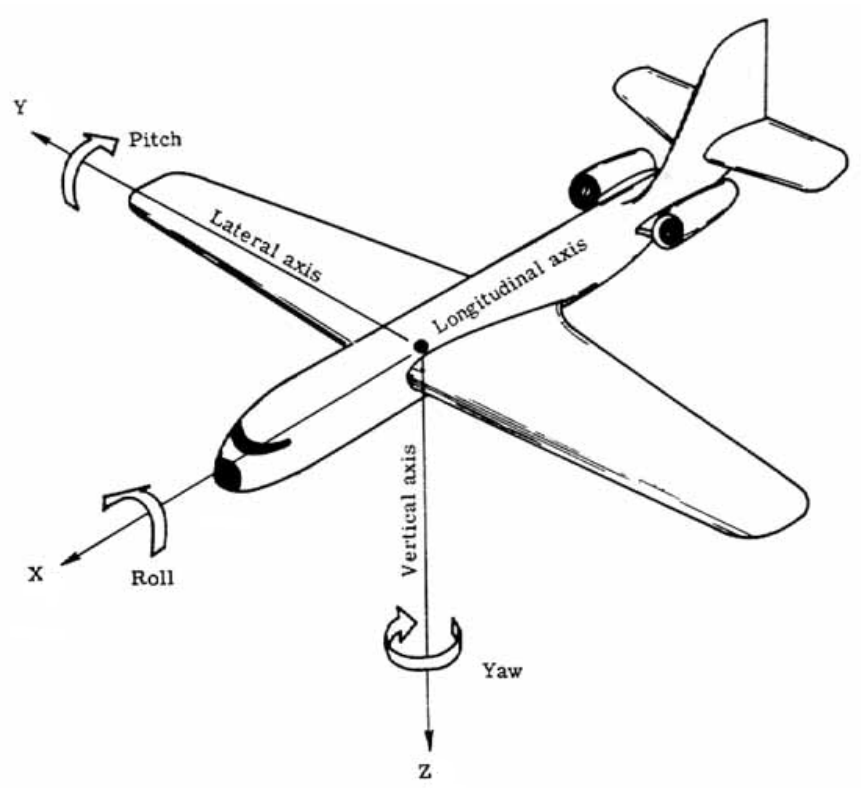

Figura 2.3: Os três eixos de rotação de uma aeronave

Na teoria de controle a estrutura básica de um sistema de controle é geralmente baseada na realimentação figura 2.4, onde $H_{a}(s)$ e $H_{c}(s)$ são sistemas lineares representados pelas funções de transferência, sendo $H_{a}(s)$ referente a parte a ser controlada e $H_{c}(s)$ a parte do controlador. Função de transferência de um sistema é o modelo matemático que constitui um método operacional para expressar a equacão diferencial ordinária que relaciona a variável de saída com a variável de entrada [29].

Em relação ao sistema da figura 2.4, o papel do controle por realimentação pode ser representado pelo piloto que verifica se a rota verdadeira da aeronave y corresponde com a rota desejada $r$ e em seguida o próprio piloto, no papel de $H_{c}$, atua no manche corrigindo o curso da aeronave por meio da superfície de controle, por exemplo, o leme de direção. O controle por realimentação também 


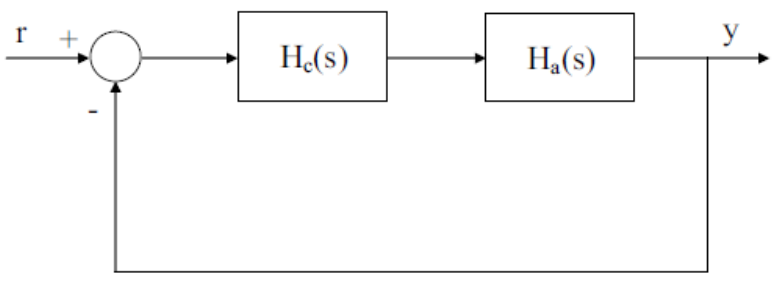

Figura 2.4: Sistema de controle da aeronave

pode ser representado pelo sistema de piloto automático de uma aeronave, o qual possui um sinal de entrada $r$ que representa a direção selecionada pelo piloto, geralmente esse sinal de entrada está relacionado à frequência de uma estação de terra NDB, VOR ou mesmo uma estação de rádio. Essa direção é constantemente comparada com a rota verdadeira da aeronave y e se há algum desvio, então o controle $H_{c}$ faz a correção da posição, por meio da atuação na superfície de controle.

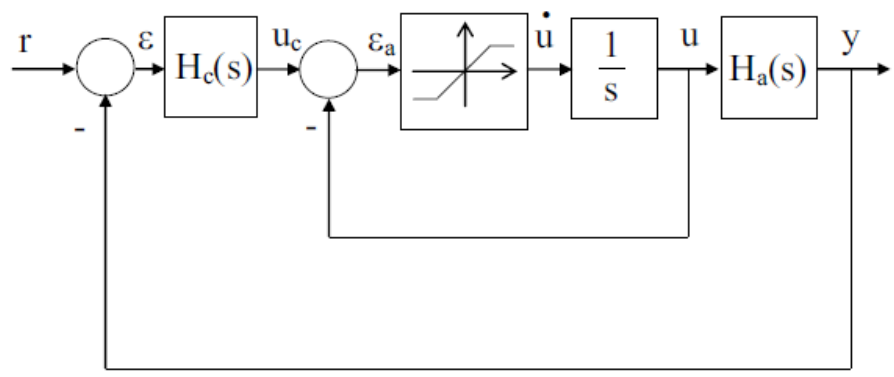

Figura 2.5: Sistema de controle da aeronave com controle do profundor

No entanto, considerando uma situação mais próxima da realidade conforme figura 2.5, verificouse que o controle automático da superfície de controle pode possuir uma não linearidade conhecida como saturação do atuador. Como u representa a defleção do leme, o controle do leme tem a finalidade de manter a deflexão $u_{c}$ determinada pelo controlador $H_{c}$ até que seja corrigido o desvio $\epsilon$ de direção da aeronave.

O que Lurie fez foi separar a parte linear da parte não linear das equações diferenciais em variáveis de estado, obtidas no processo de modelagem matemática de todo sistema ou então a partir das funções de transferência $H_{a}(s)$ e $H_{c}(s)$ juntamente com a não linearidade (as contas podem ser verificadas em [24, 32]), obtendo assim o conhecido sistema tipo Lurie da equação (2.1):

$$
\left\{\begin{array}{l}
\dot{x}=A x+b f(\sigma) \\
\sigma=c^{\prime} x
\end{array}\right.
$$

Temos na figura 2.1 a parte $L$ que é uma representação linear da dinâmica da aeronave. O controle $f(\sigma)$, na realimentação, representa uma não linearidade na atuação em uma das superfícies de comando da aeronave (profundor, aileron ou leme).

Em relação ao exemplo anterior, estudos recentes, como [34], mostram ainda a grande utilidade do problema de Lurie para se determinar a estabilidade de um certo sistema de controle de uma aeronave, a fim de se evitar fenômenos conhecidos como PIO II "Pilot Induced Oscillations"que podem causar acidentes aeronáuticos. Nesse caso o piloto humano é considerado o agente de controle $H_{c}(s)$ juntamente com a superfície de controle e a parte a ser controlada $H_{a}(s)$ é a aeronave, constando também a não linearidade. 
Assim, com um controle não linear $f(\sigma)$, muitos outros problemas práticos podem ser colocados na forma de (2.1). Ressaltando que $f$ é uma função não determinada, onde parte de sua informação pode ser obtida por meio de experimentos. Então, geralmente sabemos apenas que $f$ possui as características definidas anteriormente como $F$ (pag. 16). Para uma melhor compreensão de um sistema tipo Lurie é interessante analisarmos mais um caso prático.

\section{Exemplo 2.3. (Governador Centrifugo [18])}

A finalidade de um governador centrífugo é controlar a velocidade de máquinas. Registros mostram seu uso, inicialmente, por volta do século XVII, para o controle da velocidade de moinhos de vento, e posteriormente, a partir do século XIX, para o controle da velocidade de geradores e motores. E mais atualmente tem sido útil para experimentos no campo da ciência cognitiva. Assim, pode-se considerar o regulador centrífugo sendo o mais antigo exemplo de sistema tipo Lurie.

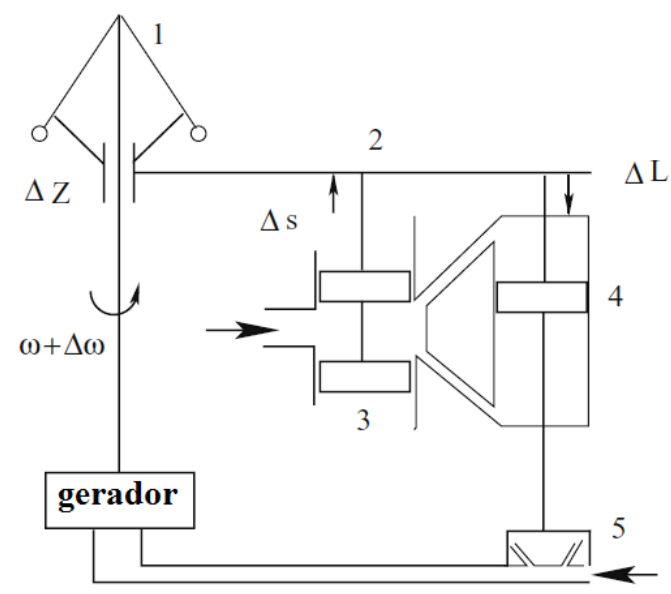

Figura 2.6: Governador centrifugo

A velocidade angular do gerador, $w$, é medida pelo regulador centrífugo, 1 . O regulador é conectado ao servo sistema hidráulico, 4, por meio do nível 2 e a válvula deslizante. O servo 4 faz o regulador 5 mover-se, quando necessário, transmitindo ao gerador uma velocidade constante. Quando a carga do gerador está reduzindo e consequentemente a sua velocidade aumentando, então a luva do governador move-se para cima, com isso levanta a válvula de deslizamento do nível 2. Assim o óleo hidráulico entra na parte superior do cilindro do servo 4 e o óleo que fica na parte inferior é drenado. Com isso o êmbolo do servo 4 desce e consequentemente reduz a passagem de gasolina, por meio do regulador 5, diminuindo a velocidade do gerador, evitando assim possiveis danos ou acidentes com uma sobrevelocidade do gerador. O processo inverso ocorre quando a carga aumenta e é necessário mais combustivel para o gerador manter sua velocidade e assim fornecer a energia correta.

Para a modelagem matemática desse sistema, detalhes em [29] e [18], considera-se a equação diferencial do gerador, a dinâmica do governador, a equação do servo e a cinemática da resposta, onde chega-se ao seguinte sistema de equações:

$$
\begin{gathered}
a_{1} \dot{\Delta w}+a_{2} \Delta w=\Delta L \\
b_{1} \Delta Z+b_{2} \Delta Z+b_{3} \Delta Z=\Delta w \\
\dot{\Delta L}=f(\Delta S) \\
\sigma=c_{1} \Delta Z-c_{2} \Delta L
\end{gathered}
$$

onde,

$\Delta w:=$ variação da velocidade do gerador.

$\Delta L:=$ variação da posição do servo.

$\Delta Z:=$ variação da posição das luvas (1). 
$\Delta S:=$ Variação da válvula de deslizamento (2).

$f(\Delta S):=$ é a quantidade de óleo que entra no cilindro por unidade de tempo.

É importante observar que $\Delta S$ é o sinal de controle que determinará a quantidade de óleo no interior do cilindro. E a função $f(\Delta S)$ é uma não linearidade do grau de abertura da válvula de deslizagem, sua forma exata não é conhecida, mas sabemos que quando $\Delta S>0$ então $f(\Delta S)>0$ (significa o aumento de óleo na parte superior do cilindro) e quando $\Delta S<0$ então $f(\Delta S)<0$ (significa a redução do óleo na parte superior do cilindro) e $f(0)=0$.

Colocando o sistema de equações (2.3) na forma do sistema (2.1), fazemos $\Delta w=x_{1}, \Delta Z=x_{2}$, $\Delta Z=x_{3}, \Delta L=x_{4}, \Delta S=\sigma ; e a_{1}, a_{2}, b_{1}, b_{2}, b_{3}, c_{1}$ e $c_{2}$ constantes, obtem-se então o seguinte sistema:

$$
\left\{\begin{aligned}
\dot{x_{1}} & =\frac{-a_{2}}{a_{1}} x_{1}-\frac{1}{a_{1}} x_{4} \\
\dot{x_{2}} & =x_{3} \\
\dot{x_{3}} & =\frac{1}{b_{1}} x_{1}-\frac{b_{3}}{b_{1}} x_{2}-\frac{b_{2}}{b_{1}} x_{3} \\
\dot{x_{4}} & =f(\sigma) \\
\sigma & =c_{1} x_{2}-c_{2} x_{4}
\end{aligned}\right.
$$

Com isso, chega-se na forma de (2.1):

$$
\begin{gathered}
x=\left(\begin{array}{l}
x_{1} \\
x_{2} \\
x_{3} \\
x_{4}
\end{array}\right), \\
A=\left(\begin{array}{cccc}
-\frac{a_{2}}{a_{1}} & 0 & 0 & -\frac{1}{a_{1}} \\
0 & 0 & 1 & 0 \\
\frac{1}{b_{1}} & -\frac{b_{3}}{b_{1}} & -\frac{b_{2}}{b_{1}} & 0 \\
0 & 0 & 0 & 0
\end{array}\right), \\
b=\left(\begin{array}{c}
0 \\
0 \\
0 \\
1
\end{array}\right), \\
c^{T}=\left(\begin{array}{llll}
0 & c_{1} & 0 & -c_{2}
\end{array}\right) .
\end{gathered}
$$

\subsection{Estabilidade Absoluta}

O conceito de Estabilidade Absoluta foi formulado pela primeira vez por Lurie e Postinikov, [24], tendo em vista a necessidade de conceituar um tipo específico de estabilidade para o problema (2.1).

Vimos no capítulo 1 o conceito de estabilidade no sentido de Lyapunov, que trata do estudo da estabilidade restrita ao comportamento local de um sistema. Já o conceito de estabilidade formulado por Lurie trata do estudo da estabilidade global assintótica de pontos de equilíbrio de sistemas tipo Lurie.

Focamos nesse trabalho, na maior parte dos casos, o problema para $f(\sigma) \in F_{\infty}$, mas a mesma definição também se aplica para os demais casos de $F$, logo, conforme as considerações anteriores, temos a seguir uma definição de estabilidade absoluta.

Definição 2.1. Se a solução zero do sistema (2.1) é globalmente assintoticamente estável para $f(\sigma) \in F_{\infty}$, então dizemos que a solução zero de (2.1) é absolutamente estável. 


\section{Exemplo 2.4. (Governador Centrifugo)}

Observemos o exemplo 2.3 da seção anterior. O resultado da modelagem do governador centrífugo, é um sistema tipo Lurie de quarta ordem:

$$
\left\{\begin{aligned}
\dot{x_{1}} & =\frac{-a_{2}}{a_{1}} x_{1}-\frac{1}{a_{1}} x_{4} \\
\dot{x_{2}} & =x_{3} \\
\dot{x_{3}} & =\frac{1}{b_{1}} x_{1}-\frac{b_{3}}{b_{1}} x_{2}-\frac{b_{2}}{b_{1}} x_{3} \\
\dot{x_{4}} & =f(\sigma) \\
\sigma & =c_{1} x_{2}-c_{2} x_{4}
\end{aligned}\right.
$$

onde:

$$
\begin{aligned}
& x=\left(\begin{array}{l}
x_{1} \\
x_{2} \\
x_{3} \\
x_{4}
\end{array}\right), \\
& A=\left(\begin{array}{cccc}
-\frac{a_{2}}{a_{1}} & 0 & 0 & -\frac{1}{a_{1}} \\
0 & 0 & 1 & 0 \\
\frac{1}{b_{1}} & -\frac{b_{3}}{b_{1}} & -\frac{b_{2}}{b_{1}} & 0 \\
0 & 0 & 0 & 0
\end{array}\right), \\
& b=\left(\begin{array}{l}
0 \\
0 \\
0 \\
1
\end{array}\right) \\
& c^{T}=\left(\begin{array}{llll}
0 & c_{1} & 0 & -c_{2}
\end{array}\right) .
\end{aligned}
$$

Quando o gerador está trabalhando em condições normais devemos ter $x_{1}=x_{2}=x_{3}=x_{4}=0$, que é o ponto de equilíbrio do sistema. Portanto para que o gerador opere perfeitamente é requerido que o ponto de equilíbrio seja absolutamente estável. Assim o problema trata de determinar condições sobre $c, A$ e b, para que a solução trivial seja absolutamente estável.

Conhecido agora o problema da estabilidade absoluta, o Problema de Lurie pode ser resumido pela seguinte pergunta: "quais são as condições necessárias e suficientes para o ponto de equilíbrio de (2.1) ser globalmente assintoticamente estável?" Então Lurie definiu Estabilidade Absoluta como o termo utilizado para a estabilidade assintótica global de um sistema tipo Lurie.

Quando falamos em condições necessárias e suficientes para estabilidade absoluta, isso significa que sem essas condições satisfeitas é impossível ter estabilidade absoluta. Condições necessárias são aquelas que existem quando um sistema é absolutamente estável, mas não garantem que esse sistema seja absolutamente estável, e condições suficientes são aquelas que levam à estabilidade absoluta, mas não garantem que para um sistema absolutamente estavel elas existam. Ilustrando, temos o seguinte:

\section{Condições Suficientes $\rightarrow$ Estabilidade Absoluta $\rightarrow$ Condições Necessárias}

Assim, conforme definido por Lefschetz [16] o Problema de Lurie é encontrar condições necessárias e suficientes para a estabilidade absoluta do ponto de equilíbrio do sistema (2.1). Portanto, pode-se entender por Problema de Lúrie o estudo da estabilidade absoluta. 
O teorema a seguir, devido a Lurie [24], é conhecido como Método da Função Lurie-Lyapunov, que utiliza o método direto de Lyapunov. Esse teorema foi um dos primeiros resultados que trazia condições, sendo nesse caso condição suficiente para estabilidade absoluta, dando bases para obtenção de novas condições.

Teorema 2.1. Se A é Hurwitz e se existe uma matriz definida positiva $B$ tal que a função de Lyapunov

$$
V(x)=\langle B x, x\rangle+\int_{0}^{\sigma(x)} f(\sigma) d \sigma,
$$

ao longo das trajetórias de (2.1) tenha a derivada

$$
\frac{d V(x)}{d t}=-\langle C x, x\rangle+\left\langle c^{T} A+2 b^{T} B, x\right\rangle f(\sigma)+\langle c, b\rangle f^{2}(\sigma),
$$

definida negativa. Então, a solução zero (ponto de equilíbrio) do sistema (2.1) é absolutamente estável.

Demonstração. Considere $\sigma=c_{1} x_{1}+\ldots+c_{n} x_{n}$ derivando $\sigma$ em relação ao tempo temos:

$$
\begin{gathered}
\dot{\sigma}=\frac{\partial \sigma}{\partial x_{1}} \dot{x_{1}}+\ldots+\frac{\partial \sigma}{\partial x_{n}} \dot{x_{n}}=c_{1} \dot{x_{1}}+\ldots+c_{n} \dot{x_{n}} \\
\dot{\sigma}=c_{1}\left(a_{11} x_{1}+a_{12} x_{2}+a_{1 n} x_{n}+b_{1} f(\sigma)\right)+\ldots+c_{n}\left(a_{n 1} x_{1}+a_{n 2} x_{2}+\ldots+a_{n n} x_{n}+b_{n} f(\sigma)\right) \\
=\left(c_{1} a_{11}+\ldots+c_{n} a_{n 1}\right) x_{1}+\ldots+\left(c_{1} a_{1 n}+\ldots+c_{n} a_{n n}\right) x_{n}+\left(c_{1} b_{1}+\ldots+c_{n} b_{n}\right) f(s)
\end{gathered}
$$

$\log$,

$$
\dot{\sigma}=\langle c, A x\rangle+\langle c, b\rangle f(\sigma)
$$

Obtemos o sistema tipo Lurie na seguinte forma:

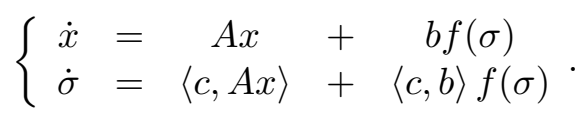

Agora tomando a equação (2.4), temos:

$$
\begin{gathered}
V(x)=\langle B x, x\rangle+\int_{0}^{\sigma(x)} f(\sigma) d \sigma \\
\frac{d V}{d t}(t)=\langle B \dot{x}, x\rangle+\langle B x, \dot{x}\rangle+f(\sigma) \dot{\sigma} \\
=\langle B(A x+b f(\sigma)), x\rangle+\langle B x, A x+b f(s)\rangle+f(\sigma)(\langle c, A x\rangle+\langle c, b\rangle f(\sigma)) \\
=\langle B A x, x\rangle+\langle+B b f(\sigma), x\rangle+\langle B x, A x\rangle+\langle B b f(\sigma), x\rangle+f(\sigma)\left\langle A^{T} c, x\right\rangle+\langle c, b\rangle f(\sigma)^{2} \\
=\left\langle\left(B A+A^{T} B\right) x, x\right\rangle+f(\sigma)\left\langle 2 B b+A^{T} c, x\right\rangle+\langle c, b\rangle f(\sigma)^{2}
\end{gathered}
$$

Fazendo $\quad-C=\left(B A+A^{T} B\right) \quad$ temos:

$$
\frac{d V}{d t}(t)=-\langle C x, x\rangle+\left\langle c^{T} A+2 b^{T} B, x\right\rangle f(\sigma)+\langle c, b\rangle f(\sigma)^{2}
$$

Agora, pelo teorema (1.3) se $\frac{d V}{d t}(t)<0$ então (2.1) é absolutamente estável.

A maior dificuldade desse método é verificar a negatividade de (2.5). Embora a conclusão do teorema seja correta, verificou-se a falha desse método, ficando estabelecida apenas uma condição 
suficiente para estabilidade absoluta. Para visualização desse fato, toma-se: $f(\sigma)=\sigma$ :

$$
\left\{\begin{array}{l}
\dot{x}=A x+b \sigma \\
\dot{\sigma}=c^{T} A x+c^{T} b \sigma
\end{array}\right.
$$

lembrando que $\sigma=c_{1} x_{1}+\ldots+c_{n} x_{n}$, tem-se:

$$
\dot{x}=\left(\begin{array}{cc}
A & b c \\
c^{T} A & c^{T} b c
\end{array}\right) x
$$

Pelo teorema (1.1) a matriz $\left(\begin{array}{cc}A & b c \\ c^{T} A & c^{T} b c\end{array}\right)$ deve ter todos seus autovalores com parte real negativa (Hurwitz), mas nesse caso, não é verdade pois:

$$
\operatorname{det}\left(\begin{array}{cc}
A & b c \\
c^{T} A & c^{T} b c
\end{array}\right)=0
$$

Observa-se então que o teorema (2.1) estabelece apenas uma condição suficiente de estabilidade absoluta, onde a condição necessária seria $\left(\begin{array}{cc}A & b c \\ c^{T} A & c^{T} b c\end{array}\right)$ ser Hurwitz.

A partir dessa ideia o teorema que segue, devido a [19] e [35] (extraídos de [18]), apresenta condições necessárias para estabilidade absoluta.

Teorema 2.2. As condições seguintes são necessárias para a estabilidade absoluta do sistema (2.1):

(1) Para todo $\epsilon>0,(0<\epsilon \leq k)$, a matriz $A+\epsilon b c^{T}$ é uma matriz Hurwitz;

(2) $\operatorname{Re} \lambda \leq 0$, onde $\lambda$ é autovalor da matriz $A$;

(3) $c^{\prime} b \leq 0$;

O próprio Lurie, após seu método inicial visto anteriormente, desenvolveu outros métodos, como: o Método da Função Lyapunov-Lurie tipo V e o Programa S, que também fornecem condições suficientes.

\subsection{Condições Necessárias e Suficientes para Estabilidade Absoluta}

Vimos na seção anterior que o Problema de Lurie trata de obter condições necessárias e suficientes para estabilidade absoluta de sistemas tipo Lurie. Ressaltando que o teorema 2.1 traz uma condição suficiente para o problema, iniciaremos a seção com um teorema para um sistema tipo Lurie num caso mais geral. Esse teorema, portanto, nos dá uma condição suficiente para estabilidade absoluta, e é uma aplicação do Método da Função Lyapunov-Lurie (Teorema 2.1).

Considere um sistema tipo Lurie numa forma mais geral, [7]:

$$
\left\{\begin{array}{l}
\dot{x}=A x-b f(\sigma) \\
\dot{\sigma}=k^{T} A x-\rho f(\sigma)
\end{array}\right.
$$

onde

$f \in F_{\infty}, \sigma: R^{n} \rightarrow R$ de classe $C^{1}, A$ é uma matriz $n x n, b \in R^{n}, k \in R^{n}$ e $\rho \in R$ são constantes.

Teorema 2.3. Suponha que a matriz A seja Hurwitz, e exista B simétrica definida positiva que satisfaz $-C=A^{T} B+B A$ (C é simétrica definida positiva) $e$

$$
\rho>\left\langle d, C^{-1} d\right\rangle
$$




$$
\text { onde } \quad d=B b-\frac{1}{2} A^{T} k
$$

Então a solução trivial de (2.8) é absolutamente estável.

Demonstração. Utilizamos essencialmente o teorema (2.1), onde primeiramente, pode-se definir uma função adequada para a aplicação do teorema (1.3) de Barbashin-Krasovski, função dada pela equação (2.4) do teorema (2.1):

$$
V(x)=\langle B x, x\rangle+\int_{0}^{\sigma(x)} f(\sigma) d \sigma
$$

temos então:

$$
\begin{gathered}
\frac{d V}{d t}(t)=\langle B \dot{x}, x\rangle+\langle B x, \dot{x}\rangle+\dot{F}(\sigma) \dot{\sigma} \\
=\langle B(A x-b f(\sigma)), x\rangle+\langle B x, A x-b f(\sigma)\rangle+f(\sigma)(\langle k, A x\rangle-\rho f(\sigma)) \\
=\langle B A x, x\rangle+\langle-B b f(\sigma), x\rangle+\langle B x, A x\rangle+\langle-B b f(\sigma), x\rangle+f(\sigma)\left\langle A^{T} k, x\right\rangle-\rho f(\sigma)^{2} \\
=\left\langle\left(B A+A^{T} B\right) x, x\right\rangle-f(\sigma)\langle 2 B b, x\rangle+f(\sigma)\left\langle A^{T} k, x\right\rangle-\rho f(\sigma)^{2} \\
=\left\langle\left(B A+A^{T} B\right) x, x\right\rangle-f(\sigma)\left\langle 2 B b-A^{T} k, x\right\rangle-\rho f(\sigma)^{2}
\end{gathered}
$$

Fazendo $\quad C=-\left(B A+A^{T} B\right) \quad$ e $\quad d=B b-\frac{1}{2} A^{T} k \quad$ temos:

$$
\frac{d V}{d t}(t)=\langle-C x, x\rangle-\langle 2 d f(\sigma), x\rangle-\rho f(\sigma)^{2}
$$

Agora basta mostrarmos que

$$
\frac{d V}{d t}(t)=\langle-C x, x\rangle-\langle 2 d f(s), x\rangle-\rho f(s)^{2}<0
$$

então:

$$
\begin{gathered}
\frac{d V}{d t}(t)=\langle-C x, x\rangle-\langle 2 d f(s), x\rangle-\rho f(s)^{2} \\
=-x^{T} C x-x^{T} 2 d f(s)-\rho f(s)^{2}=-x^{T} C x-x^{t}\left(d f(s)+f(s) d^{T}\right)-\rho f(s)^{2} \\
=-x^{T} C x-x^{T} d f(s)-x^{T} f(s) d^{T}-\rho f(s)^{2}=-x^{T} C x-f(s) d^{T} x-x^{T} d f(s)-\rho f(s)^{2}
\end{gathered}
$$

$\log \mathrm{O}$

$$
\frac{d V}{d t}(t)=-\left(x^{T} C x+f(s) d^{T} x+x^{T} d f(s)+\rho f(s)^{2}\right) .
$$

Agora devemos mostrar que a expressão

$$
\left(x^{T} C x+f(s) d^{T} x+x^{T} d f(s)+\rho f(s)^{2}\right),
$$

é positiva, para isso fazemos o seguinte:

$$
\left[x^{T}, f(s)\right]\left[\begin{array}{cc}
C & d \\
d^{T} & \rho
\end{array}\right]\left[\begin{array}{c}
x \\
f(s)
\end{array}\right],
$$

fazendo

$$
\operatorname{det}\left[\begin{array}{cc}
C & d \\
d^{T} & \rho
\end{array}\right]>0
$$

que é equivalente à:

$$
\operatorname{det}\left[\begin{array}{cc}
C^{-1} & 0 \\
0 & 1
\end{array}\right] \operatorname{det}\left[\begin{array}{cc}
C & d \\
d^{T} & \rho
\end{array}\right]>0,
$$




$$
\operatorname{det}\left[\begin{array}{cc}
I & C^{-1} d \\
d^{T} & \rho
\end{array}\right]>0
$$

(condição para que essa matriz seja definida positiva)

$$
\rho-d^{T} C^{-1} d>0
$$

$\log$,

$$
\rho>d^{T} C^{-1} d=\left\langle d, C^{-1} d\right\rangle
$$

Paralelamente no desenvolver da Conjectura de Aizerman, surgiram muitos trabalhos que se tornaram ferramentas importantes para o Problema de Lurie. Mas, a teoria pôde ser melhor generalizada a partir de 1960, onde em 1961 o romeno V.M. Popov [28] propôs um método baseado na característica em frequência da parte linear de (2.1).

$\mathrm{Na}$ década de 80 houve uma grande retomada do Problema de Lurie, onde os chineses deixaram contribuições relevantes trazendo condições necessárias e suficientes para o problema, e assim generalizando ainda melhor o problema, principalmente para um único controle não linear. Grande parte desses trabalhos encontram-se em maior detalhes na obra [18].

Assim, os próximos três teoremas, obtidos de [18], nos trazem resultados úteis para conclusões a respeito da estabilidade absoluta de sistemas de controle de três classes de problemas, bem como para problemas de linearização. Esses teoremas, que obviamente não são os únicos, são exemplos da síntese de anos de pesquisas e trabalhos que foram publicados a respeito do Problema de Lurie.

Teorema 2.4. Considere um sistema tipo Lurie de segunda ordem:

$$
\left\{\begin{array}{l}
\dot{x_{1}}=a_{11} x_{1}+a_{12} x_{2}+b_{1} f(\sigma) \\
\dot{x_{2}}=a_{21} x_{1}+a_{22} x_{2}+b_{2} f(\sigma)
\end{array}\right.
$$

Onde

$$
\begin{gathered}
f(\sigma) \in F_{\infty}, \sigma=c_{1} x_{1}+c_{2} x_{2}=c^{T} x \\
x=\left(\begin{array}{l}
x_{1} \\
x_{2}
\end{array}\right), A=\left(\begin{array}{ll}
a_{11} & a_{12} \\
a_{21} & a 22
\end{array}\right), b=\left(\begin{array}{l}
b_{1} \\
b_{2}
\end{array}\right), c^{T}=\left(\begin{array}{ll}
c_{1} & c_{2}
\end{array}\right) .
\end{gathered}
$$

Se a matriz A é Hurwitz, então a condição necessária e suficiente para a estabilidade absoluta da solução zero (ponto de equilíbrio) de (2.9) são

$$
c^{T} b \leq 0 \quad \text { e } \quad c^{T} A^{-1} b \geq 0
$$

Para a prova desse teorema Ye [37], além de um teorema devido a Krasovskii [12], utilizou também um lema que é uma das soluções para o problema de Aizerman de segunda ordem. Nesse caso, uma pequena variação do exemplo 1.10, considerando mais uma não linearidade, ou seja:

$$
\left\{\begin{array}{l}
\dot{y_{1}}=f_{1}\left(y_{1}\right)+b y_{2} \\
\dot{y_{2}}=f_{1}\left(y_{1}\right)+d y_{2}
\end{array}\right.
$$

Por meio de uma transformação em (2.9), Ye obteve um novo sistema na forma de (2.10), e assim juntamente com a mesma idéia do teorema 2.2 obteve as conclusões do teorema 2.4.

Exemplo 2.5. Verifiquemos se o ponto de equilíbrio do sistema tipo Lurie abaixo é absolutamente estável:

$$
\left\{\begin{array}{l}
\dot{x_{1}}=-2 x_{1}+x_{2}-2 f\left(x_{1}-x_{2}\right) \\
\dot{x_{2}}=-x_{1}-x_{2}+f\left(x_{1}-x_{2}\right)
\end{array}\right.
$$




$$
A=\left(\begin{array}{cc}
-2 & 1 \\
-1 & -1
\end{array}\right), b=\left(\begin{array}{c}
-2 \\
1
\end{array}\right), c^{T}=\left(\begin{array}{ll}
1 & -1
\end{array}\right)
$$

Temos

$$
\begin{gathered}
c^{T} b=\left(\begin{array}{cc}
1 & -1
\end{array}\right)\left(\begin{array}{c}
-2 \\
1
\end{array}\right)=-3<0 \\
c^{T} A^{-1} b=\left(\begin{array}{ll}
1 & -1
\end{array}\right)\left(\begin{array}{cc}
-1 & 1 \\
-1 & -2
\end{array}\right)\left(\begin{array}{c}
-2 \\
1
\end{array}\right)=3>0
\end{gathered}
$$

Como todos os autovalores de A têm parte real negativa, então A é Hurwitz, portanto o ponto de equilíbrio zero do sistema em questão é absolutamente estável.

Embora nesse trabalho não tenhamos apresentado explicitamente o critério de Popov em frequência, convém enunciarmos o teorema seguinte que utiliza o critério de Popov para trazer condições necessárias e suficientes de estabilidade absoluta.

Teorema 2.5. Considere o sistema de controle de terceira ordem:

$$
\left\{\begin{array}{l}
\dot{x}=A x+b f(\sigma) \\
\sigma=c^{T} x
\end{array}\right.
$$

onde $x \in R^{3}, b, c \in R^{3}, A \in R^{3 x 3}$ e $0<\sigma f(\sigma)<k \sigma^{2}(k \leq+\infty)$ para todo $\sigma \neq 0$.

Suponha que A tenha pelo menos um autovalor com parte real igual a zero e nenhum autovalor com parte real positiva. Se existem duas constantes $p \geq 0$ e $q$, sendo que ambas não sejam zero, tal que

$$
\operatorname{Re}\left\{(p+i \omega q) c^{T}(A-i \omega T)^{-1} b\right\}+\frac{p}{k} \leq 0 \quad \text { para } \omega \in(-\infty,+\infty),
$$

então (2.12) é a condição necessária e suficiente para a estabilidade absoluta do solução zero do sistema (2.11) no ângulo Hurwitz $[0, k]$.

Acreditava-se que a condição (2.12) era apenas uma condição suficiente, no entanto, ficou provado por [35] que a condição do Critério de Popov em frequência não era apenas suficiente, mas também necessária para estabilidade absoluta. Portanto, o problema de Lurie para essa classe de sistemas ficou resolvido completamente.

Consideremos, agora, o sistema de controle de ordem $n$ :

$$
\left\{\begin{array}{l}
\dot{x}=A x+b f(\sigma) \\
\sigma=c^{T} x
\end{array}\right.
$$

onde

$$
x \in R^{n}, \quad b, c \in R^{n}, \quad A \in R^{n x n} \quad \text { e } f(\sigma) \in F_{[0, k]} .
$$

O próximo teorema, devido a Zhang [39], nos dá condições necessárias e suficientes para o caso n-dimensional, sendo a prova desse teorema para necessariedade dada pela aplicação do teorema 2.2, e para a suficiência utiliza-se o critério em frequência de Popov.

Teorema 2.6. Se a matriz A é da forma 


$$
\left(\begin{array}{cccc}
\lambda & 0 & \cdots & 0 \\
1 & \lambda & \cdots & \vdots \\
\vdots & & \ddots & \\
0 & & \cdots & \lambda
\end{array}\right), \quad \lambda<0
$$

Então as condições necessárias e suficientes para estabilidade absoluta da solução zero do sistema (2.130) são

$$
c^{T} b \leq 0 \quad \text { e } \quad c^{T} A^{-1} b \geq 0
$$

Observemos a utilidade desse teorema considerando que a matriz (2.14) pode ser obtida a partir de uma transformação a qual conhecemos como forma de Jordan, ou seja, suponha que exista uma matriz não singular $\mathrm{P}$ tal que $J=P^{-1} A P$, sendo $\mathrm{J}$ da forma:

$$
J=\left(\begin{array}{ccc}
J_{1} & \cdots & 0 \\
\vdots & \ddots & \vdots \\
0 & \cdots & J_{m}
\end{array}\right),
$$

onde cada $J_{k}$, para $k=1,2, \ldots, m$, é da forma:

$$
J_{k}=\left(\begin{array}{cccc}
\lambda_{i} & 0 & 0 & 0 \\
1 & \lambda_{i} & 0 & 0 \\
0 & \ddots & \ddots & 0 \\
0 & 0 & 1 & \lambda_{i}
\end{array}\right)
$$

e $\lambda_{i}$ é um autovalor de $A$, para $i=1,2, \ldots, h$.

Agora, aplicando a transformação $x=P y$ ao sistema (2.13), temos:

$$
\begin{aligned}
& \left\{\begin{aligned}
P \dot{y} & =A P y+b f(\sigma) \\
\sigma & =c^{T} P y
\end{aligned}\right. \\
& \left\{\begin{array}{l}
\dot{y}=P^{-1} A P y+P^{-1} b f(\sigma) \\
\sigma=c^{T} P y
\end{array}\right.
\end{aligned}
$$

Obtemos o novo sistema:

$$
\left\{\begin{array}{l}
\dot{y}=J y+\tilde{b} f(\sigma) \\
\sigma=\tilde{c} y
\end{array}\right.
$$

onde $J=P^{-1} A P, \tilde{b}=P^{-1} b$ e $\tilde{c}=c^{T} P$.

Verifica-se ainda que as condições (2.15) não se alteram, pois

$$
\tilde{c}^{T} \tilde{b}=c^{T} P P^{-1} b=c^{T} b
$$

$\mathrm{e}$

$$
\tilde{c}^{T} J^{-1} \tilde{b}=c^{T} P P^{-1} A-1 P P^{-1} b=c^{T} A^{-1} b .
$$

Portanto, a partir desse teorema e da ideia da transformação anterior utilizando a forma de Jordan, generaliza-se o Problema de Lurie (2.13) para dimensão n. 


\section{Capítulo 3}

\section{O Problema de Lurie e as Redes Neurais de Hopfield}

Após iniciarmos uma breve viagem a partir da década de 40 onde pudemos conhecer um pouco sobre o Problema de Lurie, o qual se iniciou por meio de um problema de controle automático de aeronaves, nesse último capítulo vamos fazer uma parada no Problema de Lurie mais atual, encerrando nossa viagem. Teremos a partir de agora o ínicio de onde o Problema de Lurie pode ser utilizado em problemas de estabilidade de redes neurais. Essas fazem uma analogia ao cérebro humano. Nesse capítulo teremos inicialmente o Problema de Lurie com múltiplos controles que ainda é o centro da atenção de muitos pesquisadores. Em seguida conheceremos alguns conceitos básicos sobre redes neurais de uma forma geral e depois analisaremos a rede de Hopfield desde sua modelagem até algumas questões relevantes sobre sua estabilidade. Na úlitma seção relacionaremos o Problema de Lurie com a Rede Neural de Hopfield, onde veremos que, de fato, ela pode ser vista como um sistema tipo Lurie. E finalmente teremos uma aplicação à rede de Hopfield de um teorema desenvolvido dentro da teoria de sistemas tipo Lurie.

\subsection{O Problema de Lurie com Múltiplos Controles}

A pesquisa que envolve o Problema de Lurie para um único controle já adquiriu uma grande maturidade no que diz respeito à resolução do problema com generalizações bastantes sólidas no meio acadêmico, como vimos no capítulo anterior. Agora, nós lidaremos um pouco com o caso multivariável, ou seja, com mais de um controle não linear, que é fundamental para entendermos o modelo matemático de Hopfield e como esse modelo se relaciona com o Problema de Lurie. Para múltiplos controles o Problema de Lurie ainda não está resolvido por completo, sendo que muitos novos resultados vem surgindo, objetivando-se a generalização do problema e a extensão dos resultados de casos de um único controle para múltiplos controles. Os resultados expostos nessa seção foram extraídos de [18].

Consideremos a partir de agora o seguinte sistema tipo Lurie com $m$ controles não lineares:

$$
\left\{\begin{array}{l}
\dot{x}=A x+\sum_{j=1}^{m} b_{j} f_{j}\left(\sigma_{j}\right) \\
\sigma_{j}=c_{j}^{T} x=\sum_{i=1}^{n} c_{i j} x_{i}, \quad j=1, \ldots, m,
\end{array}\right.
$$

onde

$$
\begin{gathered}
A \in R^{n x n}, \quad x=\left(x_{1}, \ldots, x_{n}\right)^{T}, \quad b_{j}=\left(b_{1 j}, \ldots, b_{n j}\right)^{T}, \quad c_{j}=\left(c_{1 j}, \ldots, c_{n j}\right)^{T}, \\
f_{j} \in F_{\infty}:=\left\{f: f(0)=0, f(\sigma) \sigma>0, \sigma \neq 0, f(\sigma) \in C\left[(-\infty,+\infty), R^{1}\right]\right\}, \\
\operatorname{Re} \lambda(A) \leq 0 .
\end{gathered}
$$

Sabemos que o Problema de Lurie trata de determinar condições necessárias e suficientes para 
estabilidade absoluta, onde a partir da verificação da negatividade da equação (2.5) obtemos conclusões sobre a estabilidade absoluta, mas devido a grande dificuldade dessa verificação novas técnicas foram surgindo. Por volta de 1979 ZHAO [40] (extraído de [18]), obteve um importante resultado em relação a negatividade de (2.5), concluindo que $U(x)=\langle C x, x\rangle-\left\langle c^{T} A+2 b^{T} B, x\right\rangle f(\sigma)-$ $\langle c, b\rangle f^{2}(\sigma) \geq 0$ quando $c^{\prime} x=0$, ou seja, $\mathrm{U}(\mathrm{x})$ é semi-positiva definida no hiperplano $\sigma=0$.

Consideraremos então, uma análise em relação a $\sigma=c^{T} x \rightarrow 0$ quando $t \rightarrow 0$, idéia que também pode ser aplicada inicialmente ao caso com um único controle. A seguir definiremos o conjunto de soluções no hiperplano $\sigma=0$ e uma definição de estabilidade absoluta com base nesse conjunto.

Sejam:

$$
\begin{gathered}
\Omega_{j}=\left\{x: \sigma_{j}=c_{j}^{T} x=0\right\}, \\
\Omega=\left\{x:\|\sigma\|=\sum_{j=1}^{m}\left|\sigma_{j}\right|=\sum_{j=1}^{m}\left|c_{j}^{T} x\right|=0\right\} .
\end{gathered}
$$

Definição 3.1. A solução zero de (3.1) é dita absolutamente estável para o conjunto $\Omega\left(\Omega_{j}\right)$ se para todo $\epsilon>0$, existe $\delta>0$ tal que para qualquer $x_{0} \in R^{n}$ com $\left\|x_{0}\right\|<\delta$ e para qualquer $f(\sigma) \in F_{\infty} a$ distância da solução $x(t)=x\left(t ; t_{0}, x_{0}\right)$ de (2.1) ao conjunto $\Omega\left(\Omega_{j}\right)$ satisfaz:

$$
\rho(x, \Omega):=\sum_{j=1}^{m}\left|c_{j}^{T} x(t)\right|<\epsilon \quad\left(\rho\left(x, \Omega_{j}\right):=\left|c_{j}^{T} x(t)\right|<\epsilon\right),
$$

$e$

$$
\lim _{t \rightarrow+\infty} \sum_{j=1}^{m}\left|c_{j}^{T} x(t)\right|=0 \quad\left(\lim _{t \rightarrow+\infty}\left|c_{j}^{T} x(t)\right|=0\right) .
$$

Utilizando essa definição o teorema a seguir traz condições necessárias e suficientes para a estabilidade absoluta da solução nula do sistema (3.1), sendo que a mesma idéia pode ser aplicada a sistemas com um único controle (2.1) onde a demonstração é semelhante.

Teorema 3.1. As condições necessárias e suficientes para estabilidade absoluta da solução zero do sistema (3.1) são dadas por

1. $B=A+\sum_{j=1}^{m} \theta_{j} b_{j} c_{j}^{T}$ é Hurwitz $\operatorname{com} \theta_{j}=1$ ou $\theta_{j}=0, j=1, \ldots, m$;

2. A solução zero de (3.1) é absolutamente estável para $\Omega$.

\section{Demonstração. Necessariedade.}

1) verificando se estabilidade absoluta $\rightarrow$ condição 1.

No caso $\operatorname{Re} \lambda<0$, nós tomamos $\theta_{j}=0, j=1, \ldots, m$, então temos $B=A$. Assim B é Hurwitz. No caso $\operatorname{Re} \lambda \geq 0$, nós tomamos algum $\theta_{j}=1$. Seja em (3.1) $f_{j}\left(\sigma_{j}\right)=\sigma_{j}=c_{j}^{t} x(j=1, \ldots m)$. Então (3.1) pode ser transformado em

$$
\dot{x}=\left(A+\sum_{j=1}^{m} \theta_{j} b_{j} c_{j}^{T}\right) x
$$


Portanto, $B=A+\sum_{j=1}^{m} \theta_{j} b_{j} c_{j}^{T}$ é Hurwitz.

2) verificando se estabilidade absoluta $\rightarrow$ estabilidade absoluta para $\Omega$.

Para todo $\epsilon>0$, tomando

$$
\tilde{\epsilon}=\frac{\epsilon}{\sum_{j=1}^{m}\left\|c_{j}^{T}\right\|},
$$

existe $\delta(\tilde{\epsilon})>0$ tal que para $\left\|x_{0}\right\|<\delta(\tilde{\epsilon}),\|x(t)\|:=\left\|x\left(t, t_{0}, x_{0}\right)\right\|:=\sum_{j=1}^{n}\left|x_{j}(t)\right|<\tilde{\epsilon}$ para todo $t \geq t_{0}$.

Isto implica que

$$
\sum_{j=1}^{m}\left\|c_{j}^{T} x(t)\right\| \leq \sum_{j=1}^{m}\left\|c_{j}^{t}\right\| \cdot\|x(t)\| \leq \sum_{j=1}^{m}\left\|c_{j}^{t}\right\| \tilde{\epsilon}=\epsilon
$$

para todo $t \geq t_{0}$.

Além disso, uma vez que a solução nula é absolutamente estável, devemos ter $\lim _{t \rightarrow+\infty}\|x(t)\|=$ 0 para todo $x_{0} \in R^{n}$, teremos

$$
0 \leq \lim _{t \rightarrow+\infty} \sum_{j=1}^{m}\left\|c_{j}^{T} x(t)\right\| \leq \sum_{j=1}^{m}\left\|c_{j}^{T}\right\| \lim _{t \rightarrow+\infty}\|x(t)\|=0 .
$$

Consequentemente, a solução zero de (3.1) é absolutamente estável para $\Omega$.

\section{Suficiência.}

De acordo com a fórmula da variação das constantes, a solução $x(t):=x\left(t, t_{0}, x_{0}\right)$ de $(3.1)$ satisfaz

$$
\left.x(t)=e^{B\left(t-t_{0}\right)} x_{0}+\int_{t_{0}}^{t} e^{B(t-\tau)} \sum_{j=1}^{m}\left[b_{j} f_{j}\left(\sigma_{j}(\tau)\right)\right]-\theta_{j} b_{j} \sigma_{j}(\tau)\right] d \tau
$$

Sendo $B$ Hurwitz, existe constantes $M \geq 1$ e $\alpha>0$ tal que

$$
\left\|e^{B\left(t-t_{0}\right)}\right\| \leq M e^{-\alpha\left(t-t_{0}\right)}, \quad t \geq t_{0}
$$

Vamos definir $\sigma_{j}(t)=\sigma_{j}\left(t, t_{0}, x_{0}\right)$. Desde que $\sigma=\sum_{j=1}^{m}\left|\sigma_{j}(t)\right| \rightarrow 0$ quando $t \rightarrow+\infty$, temos $\lim _{t \rightarrow \infty} \sigma_{j}(t)=0$. Pelo fato de $\sigma_{j}(t)$ ser continuamente dependente em $x_{0}$, e $f_{j}\left(\sigma_{j}(t)\right)$ ser uma função contínua composta de $x_{0}$ e $f_{j}\left(\sigma_{j}(t)\right) \rightarrow \infty$ quando $t \rightarrow \infty$, então para qualquer $\epsilon>0$, existe $\delta_{1}(\epsilon)>0$ e $t_{1}>t_{0}$ tal que $\left\|x_{0}\right\|<\delta(\epsilon)$ implica

$$
\begin{gathered}
\left\|e^{B\left(t-t_{0}\right)} x_{0}\right\| \leq\left\|e^{B\left(t-t_{0}\right)}\right\| \cdot\left\|x_{0}\right\|<\frac{\epsilon}{3} \quad \text { para } \quad t \geq t_{0} . \\
\int_{t_{0}}^{t} e^{-\alpha(t-\tau)}\left[\sum_{j=1}^{m}\left\|b_{j} f_{j}\left(\sigma_{j}(\tau)\right)\right\|+\sum_{j=1}^{m} \theta_{j}\left\|b_{j} \sigma_{j}(\tau)\right\|\right] d \tau<\frac{\epsilon}{3} \quad \text { para } \quad t_{0} \leq t_{1}<t \\
\int_{t_{1}}^{t} e^{-\alpha(t-\tau)}\left[\sum_{j=1}^{m}\left\|b_{j} f_{j}\left(\sigma_{j}(\tau)\right)\right\|+\sum_{j=1}^{m} \theta_{j}\left\|b_{j} \sigma_{j}(\tau)\right\|\right] d \tau<\frac{\epsilon}{3} \quad \text { para } \quad t \geq t_{1} .
\end{gathered}
$$

Assim, temos 


$$
\begin{gathered}
\|x(t)\| \leq\left\|e^{B\left(t-t_{0}\right)} x_{0}\right\|+\int_{t_{0}}^{t} M e^{-\alpha(t-\tau)}\left[\sum_{j=1}^{m}\left\|b_{j} f_{j}\left(\sigma_{j}(\tau)\right)\right\|+\sum_{j=1}^{m} \theta_{j}\left\|b_{j} \sigma_{j}(\tau)\right\|\right] d \tau \\
+\int_{t_{1}}^{t} M e^{-\alpha(t-\tau)}\left[\sum_{j=1}^{m}\left\|b_{j} f_{j}\left(\sigma_{j}(\tau)\right)\right\|+\sum_{j=1}^{m} \theta_{j}\left\|b_{j} \sigma_{j}(\tau)\right\|\right] d \tau \\
<\frac{\epsilon}{3}+\frac{\epsilon}{3}+\frac{\epsilon}{3}
\end{gathered}
$$

Para qualquer $x_{0} \in R^{n}$, pela regua de L'hospital, nos obtemos

$$
\begin{gathered}
0 \leq \lim _{t \rightarrow+\infty}\|x(t)\| \leq \lim _{t \rightarrow+\infty} M e^{-\alpha\left(t-t_{0}\right)} \\
+\int_{t_{0}}^{t} M e^{-\alpha(t-\tau)}\left[\sum_{j=1}^{m}\left\|b_{j} f_{j}\left(\sigma_{j}(\tau)\right)\right\|+\sum_{j=1}^{m} \theta_{j}\left\|b_{j} \sigma_{j}(\tau)\right\|\right] d \tau=0 .
\end{gathered}
$$

Assim, a solução zero de (3.1) é absolutamente estável.

Sendo o teorema 3.1 uma base teórica para se trabalhar com o conjunto $\Omega$, em seguida os autores de [18] também definem uma função de Lyapunov nesse conjunto para a busca de condições necessárias e suficientes para a estabilidade absoluta de sistemas tipo Lurie com múltiplos controles.

Trabalharemos, a seguir, com funções que nem sempre serão diferenciáveis num dado ponto, por exemplo, $V(x(t))=|x|$, mas é possível verificar sua monotocidade (crescência ou decrecência) por meio da derivada dini [13] e [18]. Consideraremos essas funções como um caso especial de funções de Lyapunov, onde existe a dirivada superior pela direita de tal função, a qual pode-se definir por

$$
D^{+} V=\lim _{\sup } \rightarrow 0^{+} \frac{V(t+h)-v(t)}{h} .
$$

Prova-se em [13] e [18] que a relação de monotocidade de $V$ pode ser definida pelo sinal da derivada dini, ou seja, para uma $V(t) \in C[I, R], \quad I=\left[t_{0},+\infty\right) V$ será monótona não decrescente (não crescente) se $D^{+} V \geq 0\left(D^{+} V \leq 0\right)$.

As dificuldade do Problema de Lurie se dá principalmente pelo fato da indeterminação da função $f$, mas também pelo fato das variáveis não serem separadas, a fim de contornar esse problema pode-se fazer uma transformação em 3.1, onde obtem-se novos resultados para o caso de múltiplos controles, essa idéia também aplica-se ao caso de um único controle.

Sem perda de generalidade assumimos que $c_{i}=\left(c_{i 1}, \ldots, c_{i n}\right)(i=1,2, \ldots, m)$, são linearmente independentes, e vamos considerar a seguinte transformação a partir de (3.1):

$$
y=G\left(g_{i j}\right) x, \quad x, y \in R^{n}, G \in R^{n x n}
$$

onde

$$
g_{i j}=\left\{\begin{array}{cc}
1, & i=1, \ldots, n-m, \\
c_{j}, & i=n-m+1, \ldots, n, \\
0, & \text { c.c. }
\end{array}\right.
$$

Para não haver confusão com índices na função $f$ se $m<n$, tomamos

$$
\tilde{f}_{i+1}=f_{i} \quad i=1, \ldots, n-1 .
$$


Então, o sistema (3.1) pode ser transformado na seguinte forma:

$$
\dot{y}=\tilde{A} y+\sum_{j=n-m+1}^{n} \tilde{b}_{j} \tilde{f}_{j}\left(y_{j}\right),
$$

em forma vetorial temos:

$$
\dot{y}_{i}=\sum_{j=1}^{n} \tilde{a}_{i j} y_{j}+\sum_{j=n-m+1}^{n} \tilde{b}_{i j} \tilde{f}_{j}\left(y_{j}\right) .
$$

O teorema seguinte fornece uma condição suficiente para a estabilidade absoluta do caso (3.3), para sua melhor compreensão é recomendável um estudo mais aprofundado a respeito da estabilidade assintótica global de sistemas com variáveis separáveis (veja [18]) e também um estudo sobre um tipo de matriz conhecida por M-matriz (veja [18] ou [30])

Teorema 3.2. Suponha que

1. $\tilde{A}=\left(\tilde{a}_{i j}\right)_{n x n}$ é uma Hurwitz matriz,

2. Existe uma constante $r_{j} \geq 0(j=1, \ldots, n-m), r_{j}>0(j=n-m+1, \ldots, n)$ tal que

$$
\left\{\begin{array}{l}
r_{j} \tilde{a}_{j j}+\sum_{i=1, i \neq j}^{n} r_{i}\left|\tilde{a}_{i j}\right| \leq 0, \quad j=1, \ldots, n-m, \\
r_{j} \tilde{a}_{j j}+\sum_{i=1, i \neq j}^{n} r_{i}\left|\tilde{a}_{i j}\right|<0, \quad j=n-m+1, \ldots, n, \\
r_{j} \tilde{b}_{j j}+\sum_{i=1, i \neq j}^{n} r_{i}\left|\tilde{b}_{i j}\right| \leq 0, \quad j=n-m+1, \ldots, n,
\end{array}\right.
$$

ou

$$
\left\{\begin{array}{l}
r_{j} \tilde{a}_{j j}+\sum_{i=1, i \neq j}^{n} r_{i}\left|\tilde{a}_{i j}\right| \leq 0, \quad j=1, \ldots, n-m, \\
r_{j} \tilde{a}_{j j}+\sum_{i=1, i \neq j}^{n} r_{i}\left|\tilde{a}_{i j}\right| \leq 0, \quad j=n-m+1, \ldots, n, \\
r_{j} \tilde{b}_{j j}+\sum_{i=1, i \neq j}^{n} r_{i}\left|\tilde{b}_{i j}\right|<0, \quad j=n-m+1, \ldots, n .
\end{array}\right.
$$

Então a solução zero do sistema (3.3) é absolutamente estável.

Demonstração. Constroi-se uma função de Lyapunov:

$$
V=\sum_{i=1}^{n} r_{i}\left|y_{i}\right|
$$

Tem-se: $V=\sum_{i=1}^{n} r_{i}\left|x_{i}\right| \leq \sum_{i=n-m+1}^{n} r_{i}\left|y_{i}\right| \rightarrow+\infty$ quando $\sum_{i=n-m+1}^{n}\left|x_{i}\right| \rightarrow+\infty$. Isso mostra que $V$ é ilimitada positiva definida para $y_{n-m+1}, \ldots, y_{n}$.

$\mathrm{Se}$

$$
\begin{gathered}
\left.D^{+} V(y)\right|_{3.3} \leq \sum_{j=1}^{n}\left[r_{j} \tilde{a}_{j j}+\sum_{i=1, i \neq j}^{n} r_{i}\left|\tilde{a}_{i j}\right|\right]\left|y_{j}\right| \\
+\sum_{l=n-m+1}^{n}\left[r_{l} \tilde{b}_{l l}+\sum_{i=1, i \neq l}^{n} r_{i}\left|\tilde{b}_{i l}\right|\right]\left|\tilde{f}_{l}\left(y_{l}\right)\right|<0 \quad \text { para } \sum_{j=n-m+1}^{n}\left|y_{j}\right| \neq 0,
\end{gathered}
$$

então a solução zero de (3.3) é absolutamente estável com respeito à $y_{n-m+1}, \ldots, y_{n}$. Desde que a matriz $\tilde{A}$ seja Hurwitz, existe $M \geq 1$ e $\mu>0$ tal que

$$
\left\|e^{\tilde{A}\left(t-t_{o}\right)}\right\| \leq M e^{-\mu\left(t-t_{0}\right)} .
$$


A solução de (3.3) pode ser expressa na forma:

$$
y\left(t, t_{0}, y_{0}\right)=e^{\tilde{A}\left(t-t_{0}\right)} y_{0}+\int_{t_{0}}^{t} e^{\tilde{A}(t-\tau)} \sum_{j=n-m+1}^{n} b_{j} f_{j}\left(y_{j}\right) d \tau .
$$

Seguindo a prova de suficiência do teorema (3.1) prova-se que a solução zero de (3.3) é absolutamente estável.

Exemplo 3.1. Seja o sistema:

$$
\left\{\begin{array}{l}
\dot{x}_{1}=-x_{1}-2 f_{1}\left(x_{1}\right)+2 f_{2}\left(x_{2}\right) \\
\dot{x}_{2}=-x_{2}+2 f_{1}\left(x_{1}\right)-2 f_{2}\left(x_{2}\right)
\end{array},\right.
$$

onde $f_{1}, f_{2} \in F_{\infty}$.

Aplicando o teorema (3.2), temos:

$$
\begin{aligned}
& {\left[\begin{array}{ll}
\tilde{a}_{11} & \tilde{a}_{12} \\
\tilde{a}_{21} & \tilde{a}_{22}
\end{array}\right]=\left[\begin{array}{cc}
-1 & 0 \\
0 & -1
\end{array}\right]} \\
& {\left[\begin{array}{ll}
\tilde{b}_{11} & \tilde{b}_{12} \\
\tilde{b}_{21} & \tilde{b}_{22}
\end{array}\right]=\left[\begin{array}{cc}
-2 & 2 \\
2 & -2
\end{array}\right]}
\end{aligned}
$$

Tomando $r_{1}=1$ e $r_{2}=1$, temos:

$$
\begin{aligned}
& r_{j} \tilde{a}_{j j}+\sum_{i=1, i \neq j}^{n} r_{i}\left|\tilde{a}_{i j}\right|<0, \text { pois: } \\
& j=1, \\
& r_{1} \tilde{a}_{11}+r_{2}\left|\tilde{a}_{21}\right|=-1, \\
& j=2, \\
& r_{2} \tilde{a}_{22}+r_{1}\left|\tilde{a}_{12}\right|=-1 ; \\
& r_{j} \tilde{b}_{j j}+\sum_{i=1, i \neq j}^{n} r_{i}\left|\tilde{b}_{i j}\right|=0, \text { pois: } \\
& j=1, \\
& r_{1} \tilde{b}_{11}+r_{2}\left|\tilde{b}_{21}\right|=0, \\
& j=2, \\
& r_{2} \tilde{b}_{22}+r_{1}\left|\tilde{b}_{12}\right|=0 ;
\end{aligned}
$$

que satisfaz as condições do teorema (3.2), portanto a solução zero do sistema é absolutamente estável.

A partir da equação 3.3 o Problema de Lurie começa a ter uma relação com a Rede Neural de Hopfield, onde veremos com maiores detalhes nas seções seguintes. Na seção 3.5 teremos a continuidade do Problema de Lurie com uma aplicação à rede neural de Hopfield utilizando um teorema que é uma sequência dos teoremas anteriores.

\subsection{Conceitos Básicos de Redes Neurais Artificiais}

A idéia das Redes Neurais Artificiais (RNA) surgiu pela primeira vez a partir dos artigos de McCulloch e Pitts (1943), onde podemos defini-las como técnicas computacionais que apresentam um modelo matemático inspirado na estrutura neural de organismos inteligentes e que adquirem conhecimento através da experiência. Uma grande RNA pode ter centenas ou milhares de unidades de processamento, já o cérebro de um mamífero pode ter muitos bilhões de neurônios. 
Primeiramente para compreendermos uma RNA, precismos antes conhecer o neurônio biológico. Compondo o sistema nervoso os neurônios têm um papel essencial na determinação do funcionamento e comportamento do corpo humano e do raciocínio. Os neurônios são formados pelos dendritos, que são um conjunto de terminais de entrada que recebem estímulos, que são sinais em forma de pulsos elétricos, transmitidos de outros neurôneos; pelo corpo central conhecido como soma que é responsável por coletar e combinar informações vindas de outros neurônios que são recebidos pelos receptores de sinais através dos dentritos; e pelos axônios que são longos terminais de saída responsáveis por transmitir os estímulos para outros neurônios por meio dos ramos finais.

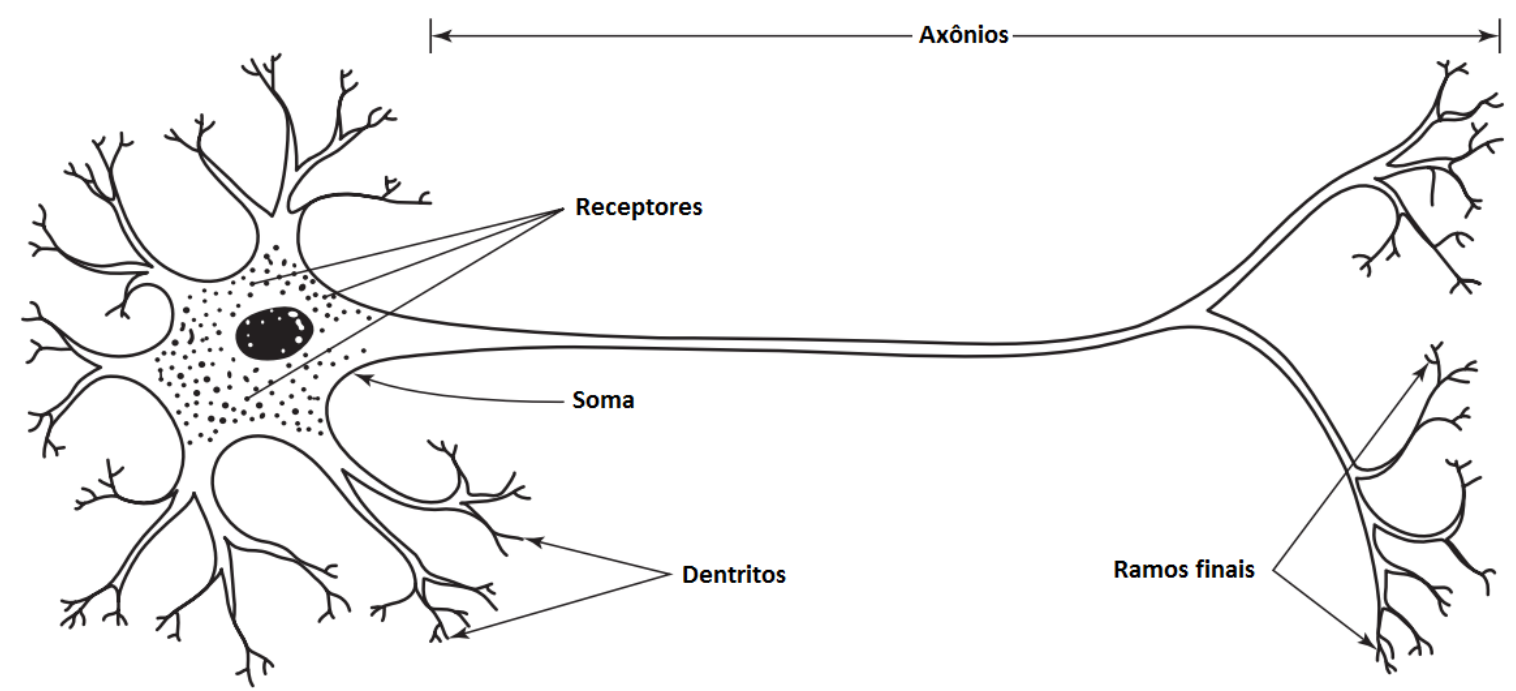

Figura 3.1: Neurônio biológico

Os neurônios se comunicam através de sinapses. Sinapse é a região onde dois neurônios entram em contato e através da qual os impulsos nervosos são transmitidos entre eles. Os impulsos recebidos por um neurônio A, em um determinado momento, são processados, e atingindo um dado limiar de ação, o neurônio A dispara, produzindo uma substância neurotransmissora que flui do corpo celular para o axônio, que pode estar conectado a um dendrito de um outro neurônio B.

Uma rede neural artificial é composta por várias unidades de processamento, cujo funcionamento é bastante simples. Essas unidades, geralmente são conectadas por canais de comunicação que estão associados a determinado peso. As unidades fazem operações apenas sobre seus dados locais, que são entradas recebidas pelas suas conexões. O comportamento inteligente de uma RNA vem das interações entre as unidades de processamento da rede.

A operação de uma unidade de processamento, proposta por McCullock e Pitts, num modelo discreto, comparada ao neurônio biológico, resumidamente, dá-se primeiramente pela apresentação de sinais na entrada $\left[x_{1}, x_{2}, \ldots, x_{n}\right]$ representando os dentritos, cada sinal é multiplicado por um número, ou peso $\left[w_{1}, w_{2}, \ldots w_{n}\right]$, que indica a sua influência na sáida da unidade, em seguida é feita a soma ponderada dos sinais $\langle w, x\rangle-t$ onde $t$ é o limitador, representando assim o corpo do neurôneo biológico, seguido da função de ativação, podendo, essa, assumir diversos tipos, produzindo um nível de atividade e se este nível de atividade exceder um certo limite, conhecido como "threshold" (fig. 3.2), a unidade produz uma determinada resposta de saída y que corresponde ao axônio.

Quanto ao processo de aprendizagem de uma RNA existem muitos algorítmos, isso é feito através de um processo iterativo de ajustes aplicado a seus pesos, o treinamento. E quanto a finalidade da aprendizagem podemos destacar a memória associativa que é análoga à memória associativa biológica, dentre as diferentes categorias existentes no cérebro.

Para o cérebro humano um exemplo de uma atividade da memória associativa seria o seguinte: Para nos lembrarmos do nome de uma pessoa, não seria tão útil determinar qual foi o nome de número 3.274 que aprendemos. Seria melhor saber que ele é o autor desse trabalho e seu nome 


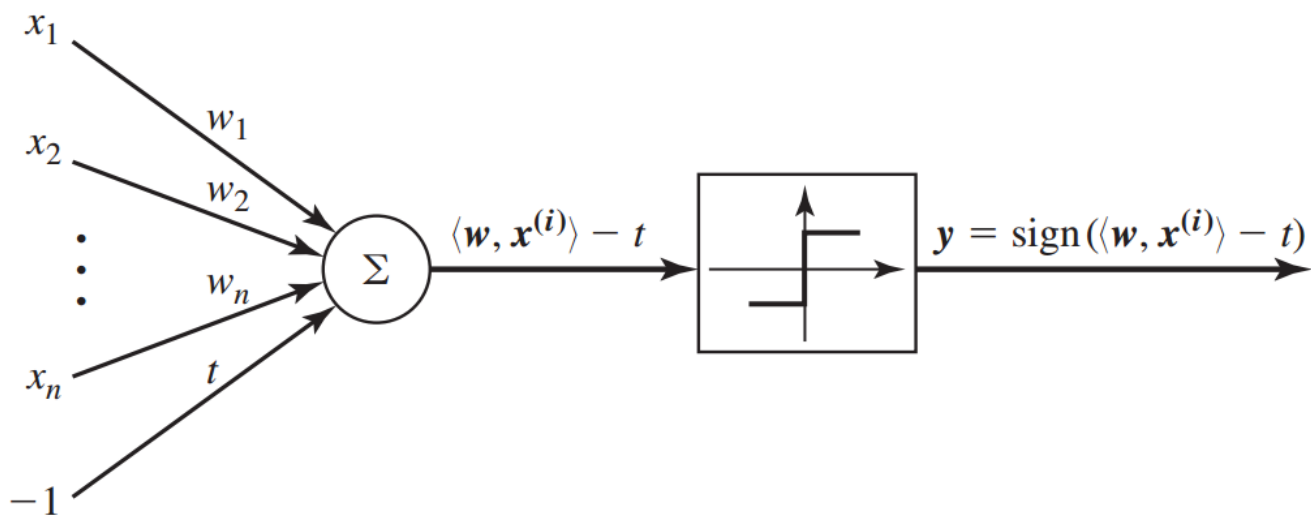

Figura 3.2: Neurônio artificial

começa com a letra "R"e termina com "L". Com essa informação, quase certamente se lembraria com sucesso de "Rafael".

Quando tratamos de RNA, memórias associativas são uma das mais importantes com uma vasta gama de aplicações em áreas como o acesso ao conteúdo de memória, reconhecimento de padrões e controle inteligente. Sendo que, na literatura, a memória associativa de uma RNA se distingue em dois tipos: memória autoassociativa e heteroassociativa.

A memória autoassociativa armazena um conjunto de padrões, em que os padrões são geralmente representados como vetores, quando um desses padrões é apresentado de forma distorcida a tarefa da RNA com memória autoassociativa será recuperar o padrão original emitindo uma saída sem distorção.

A memória heteroassociativa é uma variante da autoassocitiva que memoriza um conjunto de pares. O sistema aprende a reproduzir o segundo elemento do par mesmo que o primeiro seja apresentado contendo pequenas alterações. Esta memória heteroassociativa é também conhecida como reconhecedora de padrões, onde o primeiro elemento apresentado é o elemento a ser reconhecido e o segundo é um elemento do conjunto de padrões considerado.

Assim a operação de uma memória associativa é caracterizada por duas fases: fase de armazenamento, onde os padrões estão sendo armazenados pela RNA, e fase de recuperação, onde os padrões memorizados estão sendo recuperados em resposta a um padrão distorcido apresentado à rede. A figura 3.3 ilustra a fase de recuperação onde a entrada $x$ representa um padrão distorcido e a saída $y$ o padrão sem distorção.

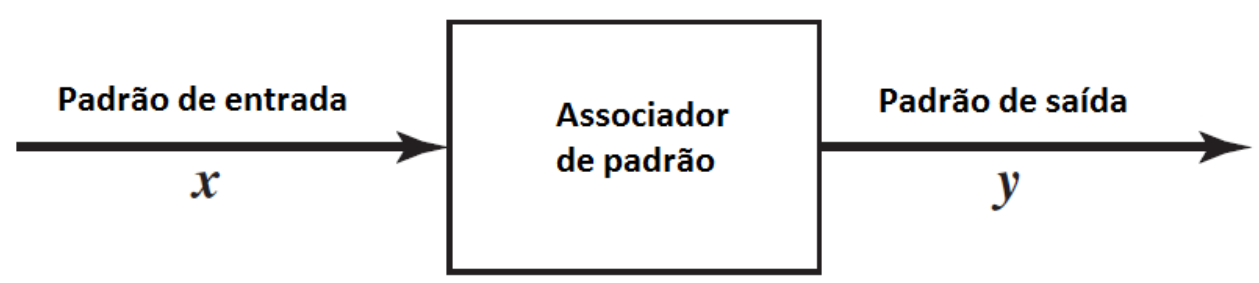

Figura 3.3: Operação do associador de padrão

\subsection{Rede Neural de Hopfield}

A Rede Neural de Hopfield (RNH) é um modelo de rede neural que foi proposto por J. J. Hopfield, em 1984 [9], que faz parte de uma área conhecida como Neurodinâmica que é o estudo de RNA como sistemas dinâmicos não lineares, com ênfase no problema da estabilidade. 
Com a publicação do artigo de Hopfield, a pesquisa na área de RNA obteve um salto, onde considerava-se a rede de Hopfield como uma memória associativa, tendo por principal finalidade a função de restaurar um padrão armazenado em resposta à apresentação de uma versão incompleta ou distorcida deste padrão. A RNH foi aplicada em várias áreas, tendo um campo de utilização muito grande, conforme [3], podemos citar algumas aplicações: implementação de sistemas de identificação de alvos militares utilizados em aeronaves modelo B-52; sistemas de autentição de usuários; exploração de petróleo; predição no mercado financeiro; reconhecimentos de faces e controle de navegação autônoma de veículos ALVINN; entre outras.

O processo de modelagem do modelo contínuo da RNH da-se através de um circuito elétrico onde sua realização pode ser observada por meio da figura 3.,4a. Observemos primeiramente o modelo do neurônio artificial da RNH na figura 3.4b. A resistêcnia $\rho_{i}$ e o capacitor $C_{i}$ em paralelo formam um filtro passa-baixa, a aplicação desse filtro pode ser interpretado como a sinapse biológica, ou seja, a constante de tempo de saída do i-ésimo neurônio biológico, sendo $\rho_{i}$ e $C_{i}$ inerentes ao amplificador $g$. A variável $u_{i}$ representa uma tensão induzida na entrada de uma função de ativação $g($.$) , e V_{i}$ é a tensão de saída que será utilizada na retroalimentação. $I_{i}$ é uma fonte externa de corrente aplicada que representa um bias, isso para uma melhor adaptação, por parte da rede neural, para o processo de aprendizado.
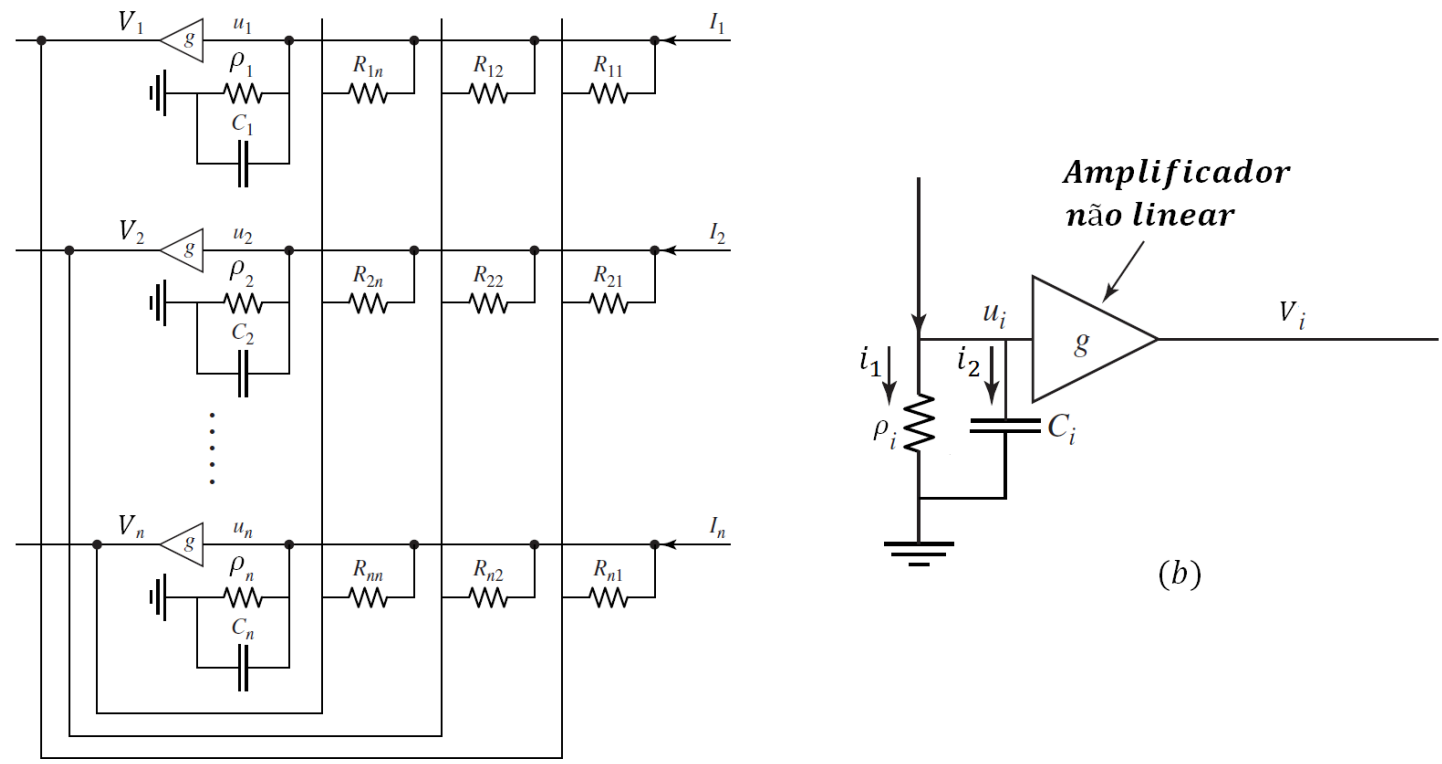

(a)

Figura 3.4: (a) realização da $R N H$ (b) neurônio da $R N H$

Basicamente a modelagem é feita a partir da circulação de corrente no circuito. A lei das correntes de Kirchhoff diz que o somatório das correntes que entram em um nó é igual ao somatório das correntes que saem. Assim a corrente através de $\rho_{i}$ é

$$
i_{1}=\frac{u_{i}}{\rho_{i}} ;
$$

a corrente que passa através de $C_{i}$ é dada por

$$
i_{2}=C_{i} \frac{d u_{i}}{d t},
$$

que é a forma de se adicionar dinâmica ao sistema (memória) que determina a taxa de variação da entrada $u_{i}$; e o somatório das correntes que fluem por $R_{i j}$ é dado pela expressão (3.4), podendo ser melhor compreendida observando a figura 3.5. 


$$
i_{3}=\frac{V_{1}-u_{i}}{R_{i 1}}+\frac{V_{2}-u_{i}}{R_{i 2}}+\ldots+\frac{V_{n}-u_{i}}{R_{i n}} .
$$

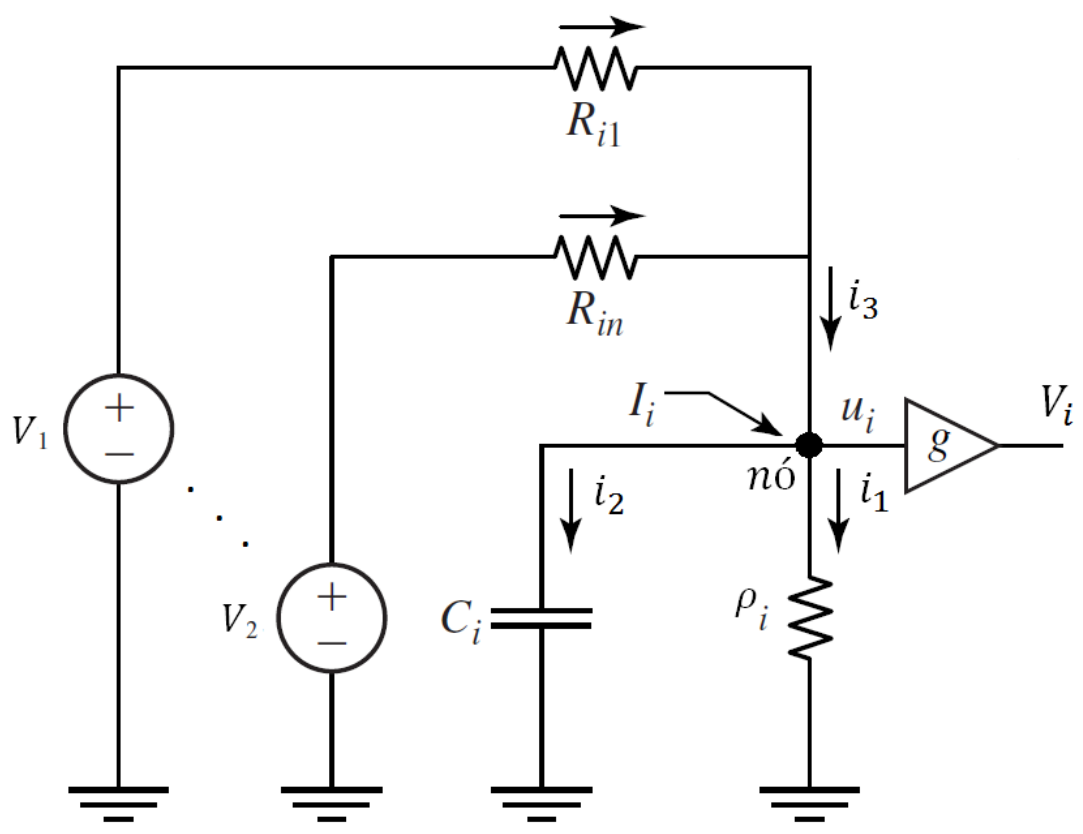

Figura 3.5: Representação de um nó no circuito de realização

Portanto pela lei de Kirchhoff temos que

$$
i_{1}+i_{2}=i_{3}+I_{i},
$$

obtemos então

$$
C_{i} \frac{d u_{i}}{d t}+\frac{u_{i}}{\rho_{i}}=\frac{V_{1}-u_{i}}{R_{i 1}}+\frac{V_{2}-u_{i}}{R_{i 2}}+\ldots+\frac{V_{n}-u_{i}}{R_{i n}}+I_{i} \quad i=1,2, \ldots, n,
$$

onde $V_{i}=g\left(u_{i}\right)$ e sua inversa $g\left(V_{i}\right)^{-1}=u_{i}$, sendo $g: R \rightarrow[0,1]$ continuamente diferenciável e monótona crescente, ou seja, $g_{i}^{\prime}\left(u_{i}\right)>0$. A função $g$ é chamada de função de ativação, geralmente escolhe-se como funções de ativação funções tipo sigmoidal.

Desenvolvendo um pouco a expressão (3.5), temos

$$
C_{i} \frac{d u_{i}}{d t}+\frac{u_{i}}{\rho_{i}}+\frac{u_{i}}{R_{i 1}}+\frac{u_{i}}{R_{i 2}}+\ldots+\frac{u_{i}}{R_{i n}}=\frac{V_{1}}{R_{i 1}}+\frac{V_{2}}{R_{i 2}}+\ldots+\frac{V_{n}}{R_{\text {in }}}+I_{i} \quad i=1,2, \ldots, n
$$

tomando

$$
T_{i j}=\frac{1}{R_{i j}}, \quad \frac{1}{R_{i}}=\sum_{j=1}^{n} T_{i j}+\frac{1}{\rho_{i}} .
$$

Substituindo na expressão (3.6), temos

$$
C_{i} \frac{d u_{i}}{d t}+\frac{u_{i}}{R_{i}}=\sum_{j=1}^{n} T_{i j} V_{j}+I_{i}, \quad i=1,2, \ldots, n .
$$

E, finalmente 


$$
C_{i} \frac{d u_{i}}{d t}=-\frac{u_{i}}{R_{i}}+\sum_{j=1}^{n} T_{i j} V_{j}+I_{i}, \quad i=1,2, \ldots, n .
$$

Esse sistema constitui o modelo matemático contínuo da Rede Neural de Hopfield. Existe também a versão discreta que é baseada no modelo de McCulloch-Pitts, a qual não trataremos nesse trabalho.
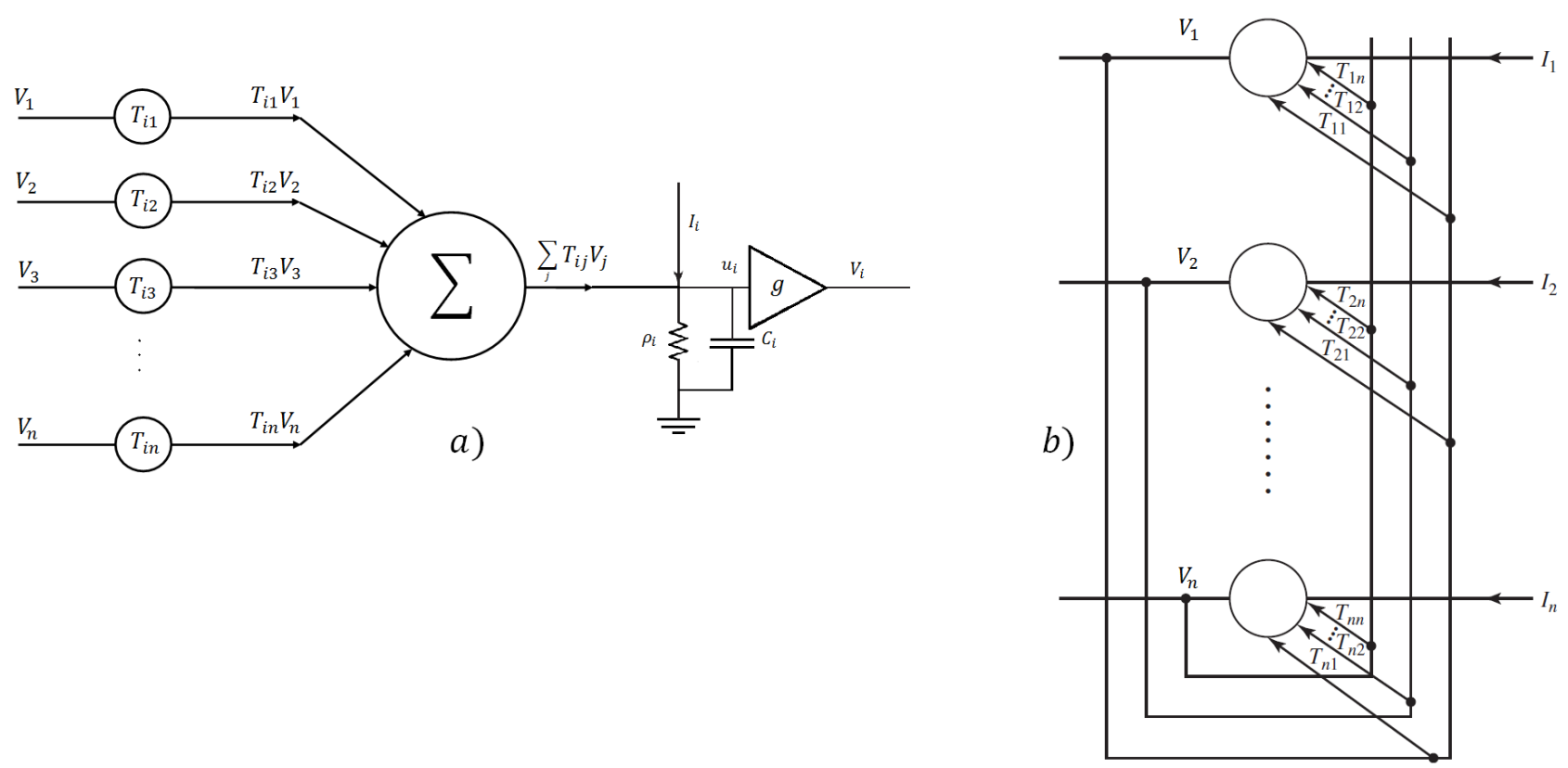

Figura 3.6: (a) neurônio da $R N H$ (b) $R N H$

Ressalta-se que $R_{i}$ não é aquela resistência em paralelo com capacitor, mas como vimos na modelagem esse valor é uma composição específica de outras resistências que compõe os pesos. Os valores $T_{i j}$ podem ser considerados os pesos sinápticos, que é dado pelo inverso das resistências, isto é, condutâncias, que recebem as realimentações, representando a força de conexão entre os neurônios.

Assim, levando em conta essas considerações, podemos ter uma representção de cada neurônio com suas realimentações por meio da figura 3.6a, e a representação da RNH conforme a figura 3.6b

\subsection{Estabilidade de Hopfield}

O problema da estabilidade da Rede Neural de Hopfield foi discutido pela primeira vez pelo próprio Hopfield e até hoje é um problema ainda em estudo devido a sua grande complexidade. Hopfield primeiramente definiu uma função a qual denominou como função de energia computacional:

$$
E(V)=-\frac{1}{2} \sum_{i=1}^{n} \sum_{j=1}^{n} T_{i j} V_{i} V_{j}-\sum_{i=1}^{n} V_{i} I_{i}+\sum_{i=1}^{n} \frac{1}{R_{i}} \int_{0}^{V_{i}} g_{i}^{-1}(s) d s,
$$

em seguida, considerando uma rede onde nenhum neurônio faz realimentação em si mesmo e a matriz de pesos sendo simétrica, Hopfield mostrou que $\frac{d E}{d t} \leq 0$ e utilizando o Princípio da Invariância de LaSalle fez considerações a respeito do comportamento assintótico da rede.

Para uma melhor compreensão, antes de generalizarmos para dimensão $n$, vamos considerar inicialmente uma RNH de 2 neurônios, tomando então a equação (3.8) para $n=2$ temos:

$$
\left\{\begin{array}{l}
C_{1} \dot{u_{1}}=-\frac{u_{1}}{R_{1}}+T_{11} V_{1}+T_{12} V_{2}+I_{1} \\
C_{2} \dot{u_{2}}=-\frac{u_{2}}{R_{2}}+T_{21} V_{1}+T_{22} V_{2}+I_{2}
\end{array}\right.
$$




$$
V_{1}=g_{1}\left(u_{1}\right), \quad V_{2}=g_{2}\left(u_{2}\right) .
$$

A função de energia computacional toma a forma:

$$
E(V)=-\frac{1}{2}\left(T_{11} V_{1} V_{1}+T_{12} V_{1} V_{2}+T_{21} V_{2} V_{1}+T_{22} V_{2} V_{2}\right)-V_{1} I_{1}-V_{2} I_{2}+\frac{1}{R_{1}} \int_{0}^{V_{1}} g_{1}^{-1}(s) d s+\frac{1}{R_{2}} \int_{0}^{V_{2}} g_{2}^{-1}(s) d s .
$$

Hopfield considerou que cada neurônio não faz realimentação em si mesmo, ou seja, $T_{11}=T_{22}=$ 0 e que a matriz de pesos $T$ é simétrica, ou seja, $T_{12}=T_{21}$, assim (3.10) pode tormar a seguinte forma:

$$
\left\{\begin{array}{l}
C_{1} \frac{d u_{1}}{d t}=-\frac{u_{1}}{R_{1}}+T_{12} V_{2}+I_{1} \\
C_{2} \frac{d u_{2}}{d t}=-\frac{u_{2}}{R_{2}}+T_{12} V_{1}+I_{2}
\end{array}\right.
$$

$\mathrm{e}$

$$
E(V)=-T_{12} V_{1} V_{2}-V_{1} I_{1}-V_{2} I_{2}+\frac{1}{R_{1}} \int_{0}^{V_{1}} g_{1}^{-1}(s) d s+\frac{1}{R_{2}} \int_{0}^{V_{2}} g_{2}^{-1}(s) d s .
$$

Agora, derivando $E$ em relação a $t$ ao longo das tragetórias de (3.11):

$$
\frac{d E}{d t}=\frac{\partial E}{\partial V_{1}} \frac{d V_{1}}{d t}+\frac{\partial E}{\partial V_{2}} \frac{d V_{2}}{d t}
$$

lembrando que $u_{1}=g_{1}^{-1}\left(V_{1}\right), \quad u_{2}=g_{2}^{-1}\left(V_{2}\right)$ e usando o teorema fundamental do cálculo nas integrais, temos:

$$
\frac{d E}{d t}=\left(-T_{12} V_{2}-I_{1}+\frac{u_{1}}{R_{1}}\right) \frac{d V_{1}}{d t}+\left(-T_{12} V_{1}-I_{2}+\frac{u_{2}}{R_{2}}\right) \frac{d V_{2}}{d t},
$$

observando, (3.11), chegamos a:

$$
\frac{d E}{d t}=-C_{1} \frac{d u_{1}}{d t} \frac{d V_{1}}{d t}-C_{2} \frac{d u_{2}}{d t} \frac{d V_{2}}{d t},
$$

sabendo que $\frac{d V_{1}}{d t}=g_{1}^{\prime}\left(u_{1}\right) \frac{u_{1}}{d t}$ e $\frac{d V_{2}}{d t}=g_{2}^{\prime}\left(u_{2}\right) \frac{u_{2}}{d t}$, obtemos

$$
\frac{d E}{d t}=-C_{1}\left(\frac{d u_{1}}{d t}\right)^{2} g_{1}^{\prime}\left(u_{1}\right)-C_{2}\left(\frac{d u_{2}}{d t}\right)^{2} g_{2}^{\prime}\left(u_{2}\right),
$$

lembrando que $g_{1}^{\prime}\left(u_{1}\right)>0$ e $g_{2}^{\prime}\left(u_{2}\right)>0$, temos:

$$
\frac{d E}{d t} \leq 0
$$

Antes de analisarmos o significado de (3.16) vamos generalizar para dimensão $n$, consideremos o modelo de Hopfield:

$$
C_{i} \frac{d u_{i}}{d t}=-\frac{u_{i}}{R_{i}}+\sum_{j=1}^{n} T_{i j} V_{j}+I_{i}, \quad i=1,2, \ldots, n .
$$

Tomando a forma original da função de energia computacional (3.9)

$$
E(V)=-\frac{1}{2} \sum_{i=1}^{n} \sum_{j=1}^{n} T_{i j} V_{i} V_{j}-\sum_{i=1}^{n} V_{i} I_{i}+\sum_{i=1}^{n} \frac{1}{R_{i}} \int_{0}^{V_{i}} g_{i}^{-1}(s) d s .
$$

Derivando $E$ em relação a $t$ ao longo das tragetórias de (3.17), analogamente à (3.12) 


$$
\frac{d E}{d t}=\sum_{i=1}^{n} \frac{\partial E}{\partial V_{i}} \frac{d V_{i}}{d t}
$$

considerando $T i j=T j i$ e $T_{i i}=0$, semelhantemente à (3.13), temos:

$$
\frac{d E}{d t}=\sum_{i=1}^{n}\left(-\sum_{j=1}^{n} T_{i j} V_{j}-I_{i}+\frac{u_{i}}{R_{i}}\right) \frac{d V_{i}}{d t}
$$

observando (3.17), temos:

$$
\frac{d E}{d t}=\sum_{i=1}^{n}-C_{i} \frac{d u_{i}}{d t} \frac{d V_{i}}{d t}
$$

Assim como em (3.15), chegamos em:

$$
\frac{d E}{d t}=-\sum_{i=1}^{n} C_{i}\left(\frac{d u_{i}}{d t}\right)^{2} g_{i}^{\prime}\left(u_{i}\right) \leq 0
$$

$\log 0$

$$
\frac{d E}{d t} \leq 0
$$

Prova-se [38] que $E$ é limitada, logo temos um tipo de função conforme definida no teorema de LaSalle. Podendo ser aplicado o Princípio da Invariância de LaSalle, assim teremos um conjunto $\omega$-limite, para

$$
\frac{d E}{d t}=0
$$

Isso acontece se, e somente se,

$$
\frac{d u_{i}}{d t}=0 \quad(i=1,2, \ldots, n) \Longleftrightarrow-\frac{u_{i}}{R_{i}}+\sum_{j=1}^{n} T_{i j} V_{j}+I_{i}=0 \quad(i=1,2, \ldots, n)
$$

Portanto a estabilidade da rede de Hopfield efetuada por Hopfiel trata de uma análise em relação ao comportamento assintótico da rede de Hopfield, onde temos movimentos para o equilíbrio ou a atração de soluções para pontos de equilíbrio, observa-se, então, que a rede procura automaticamente pontos de equilíbrio. Em outras palavras, a evolução do tempo do modelo de Hopfield contínuo descrito pelo sistema de equações diferenciais de primeira ordem não lineares pode representar uma trajetória no espaço de estados, que busca os mínimos da função de energia computacional $E$ e para em tais mínimos (ponto de equilíbrio). Assim, a Rede Neural de Hopfield pode ter pontos de equilíbrio que atraem uma vizinhança ao longo do tempo, onde interpreta-se esse fenômeno como uma evolução de um padrão imperfeito ou distorcido em direção a um padrão desejado, o equilíbrio. Com isso, tem-se então a idéia de se recuperar padrões a partir de um padrão distorcido, que nos leva a compreender a RNH como uma memória associativa.

Tendo em vista as considerações anteriores, e levando em conta a analise efetuada por Hopfield, alguns autores têm definido um tipo diferente de estabilidade [23], estabilidade no sentido de Hopfield.

Faz sentido pensar nessa idéia, pois lembramos que o Princípio de Invariancia de LaSalle não traz conclusões sobre estabilidade, logo não se pode afirmar que a rede é estável no sentido de Lyapunov, ou seja, a forma como Hopfield analisa a estabilidade da rede é diferente da análise da estabilidade no sentido de Lyapunov. Nessa direção alguns argumentos podem ser considerados:

1. A função $E$ não necessariamente é uma função de Lyapunov como definimos, pois não é 
garantido que $E>0$, ou seja, para a estabilidade no sentido de Lyapunov deve-se ter sinais contrários para $E$ e $d E / d t$ na vizinhaça de um ponto de equilíbrio, na análise de Hopfield isso não é requerido.

2. Na análise da estabilidade no sentido de Lyapunov o ponto de equilíbrio deve ser conhecido, já em relação a análise de Hopfield o ponto de equilíbrio não é conhecido, na verdade a rede de Hopfiled pode ser considerada como um método de procura por pontos de equilíbrio.

3. Outra questão é que não se pode concluir que um determinado ponto de equilíbrio seja ponto mínimo de $E$ como na estabilidade de Lyapunov, na estabilidade proposta por Hopfield poderia ser um ponto de reflexão, tendo em vista que a derivada de primeira ordem igual a zero é apenas uma condição necessária para termos um valor mínimo.

Finalmente, conforme as considerações anteriores, é interessante um estudo minucioso sobre a estabilidade da rede, a partir dessa motivação teremos a seguir a seção que encerra esse trabalho.

\subsection{Relacionando a Rede Neural de Hopfield com o Problema de Lurie}

Embora a RNH tenha se mostrado útil na função de restaurar padrões, vimos na seção anterior algumas questões, que refletem alguns problemas relacionados a sua estabilidade, problemas esses que provavelmente são os causadores para a RNH não ter sido muito eficiente para a resolução de tarefas relacionadas à recuperação de informação a partir de versões distorcidas ou ruidosas [25]. No entanto, com as diversas publicações de anos recentes, que tratam da RNH, tem-se observado grande interesse teórico e biológico pelo modelo de Hopfield.

Diretamente relacionado a esses interesses podemos citar a modelagem matemática de algumas patologias mentais utilizando-se da RNH, como exemplo o mal de Alzheimer (MA), que é uma disfunção degenerativa do cérebro ainda sem cura, e atinge milhões de pessoas ao redor do mundo. Embora o MA tenha sido documentado pela primeira vez por Alois Alzheimer cem anos atrás, o entendimento da sua causa final ainda representa um mistério para a neurobiologia. Dessa forma, a exemplo do artigo [26], é atraente a possibilidade de se trabalhar em cima de sua modelagem matemática para efetuar simulações computacionais, a fim de que seja possível realizar algumas inferências acerca da prognose dessa disfunção cerebral, diminuindo as incertezas atuais. $\mathrm{O}$ artigo [41] mostra que a modelagem de funções do cérebro utilizando RNH em conjunto de outros modelos computacionais têm se mostrado bastante útil, sendo que a partir desse ponto pode-se trabalhar na modelagem do MA e possivelmente sugerir estratégias para seu controle a partir da análise da estabilidade.

Juntamente a isso, em relação ao grande interesse teórico que a RNH tem despertado, pode-se destacar também o estudo da estabilidade absoluta da RNH com aplicação direta em problemas de otimização. Nesse caso uma das maiores dificuldades em otimizações é encontrar soluções que não sejam falsas, pois a RNH pode apresentar diversos pontos de equilíbrio, assim obtendo condições necessárias e suficientes para a estabilidade absoluta da rede esse problema pode ser superado. Para termos estabilidade absoluta é uma condição necessária que o ponto de equilíbrio seja único. Provar que o ponto de equilíbrio é único quando tratamos de funções sigmoides a teoria do ponto fixo de Brouwer é útil, mas nem sempre é uma tarefa fácil, geralmente necessita-se de ferramentas matemáticas de alta complexidade. Mas, por outro lado, se é provado que o ponto de equilíbrio é absolutamente estável, então automaticamente considera-se que o mesmo é único.

Assim, a fim de se conhecer melhor sobre a estabilidade da rede de Hopfield, demonstraremos adiante, tendo como base [18], que a RNH pode ser considerada um caso particular de sistemas tipo Lurie com múltiplicos controles. Fato que abre portas para sua análise utilizando-se da teoria de sistemas tipo Lurie, bem como, da teoria da estabilidade absoluta. 
Vejamos o modelo de Hopfield (3.8)

$$
C_{i} \frac{d u_{i}}{d t}=-\frac{u_{i}}{R_{i}}+\sum_{j=1}^{n} T_{i j} V_{j}+I_{i}, \quad i=1,2, \ldots, n .
$$

Primeiramente, lembrando que $V_{i}=g_{i}\left(u_{i}\right)$ e analisando a função $g$, temos que $g: R \rightarrow[0,1]$, continuamente diferenciável e monótona crescente, $g_{i}^{\prime}\left(u_{i}\right)>0$. Assim a função $g$ pertence à classe de funções $F_{\infty}$ do Problema de Lurie, portanto as funções do Problema de Lurie são classes de funções mais gerais que as do modelo de Hopfield:

$$
g \in F_{\infty}:=\left\{g \mid g(0)=0, u_{i} g\left(u_{i}\right)>0, g \neq 0\right\}
$$

Vamos realizar algumas transformações. Primeiro passando $C_{i}$ dividindo para o lado direito de (3.8) definimos as novas constantes:

$$
d_{i}=\frac{1}{C_{i} R_{i}}, \quad b_{i j}=\frac{T_{i j}}{C_{i}}, \quad U_{i}=\frac{I_{i}}{C_{i}}
$$

a Rede neural de Hopfield torna-se

$$
\frac{d u_{i}}{d t}=-d_{i} u_{i}+\sum_{j=1}^{n} b_{i j} g_{j}\left(u_{j}\right)+U_{i} .
$$

Para eliminar a entrada externa $U_{i}$ fazemos a seguinte transformação:

$$
u_{i}=y_{i}+\frac{U_{i}}{d_{i}}
$$

e

$$
G_{i}\left(y_{i}\right)=g_{i}\left(y_{i}+\frac{U_{i}}{d_{i}}\right)
$$

Como $y_{i}=u_{i}-\frac{U_{i}}{d_{i}}$ então $\frac{d y_{i}}{d t}=\frac{d u_{i}}{d t}$, assim substituindo em (3.23) temos:

$$
\begin{gathered}
\frac{d y_{i}}{d t}=-d_{i}\left(y_{i}+\frac{U_{i}}{d_{i}}\right)+\sum_{j=1}^{n} b_{i j} G_{j}\left(y_{j}\right)+U_{i} \\
\frac{d y_{i}}{d t}=-d_{i} y_{i}-U_{i}+\sum_{j=1}^{n} b_{i j} G_{j}\left(y_{j}\right)+U_{i} \\
\frac{d y_{i}}{d t}=-d_{i} y_{i}+\sum_{j=1}^{n} b_{i j} G_{j}\left(y_{j}\right) .
\end{gathered}
$$

Portanto, utilizando essa transformação a entrada da RNH $U_{i}$ torna-se zero, como temos em (3.24).

A princípio nosso interesse dá-se em conhecer o comportamento de soluções próximas ao ponto de equilíbrio, assim para encontrarmos o ponto de equilíbrio para o sistema (3.24) fazemos

$$
-d_{i} y_{i}+\sum_{j=1}^{n} b_{i j} G_{j}\left(y_{j}\right)=0
$$

Em geral, para o Problema de Lurie, assume-se que o ponto de equilíbrio de interesse esteja localizado na origem do $R^{n}$, mas a partir de (3.24) se isto não ocorrer pode-se fazer uma translação utilizando uma mudança de variáveis adequada. Seja, então, $y=\left[y_{1}, y_{2}, \ldots, y_{n}\right]^{t} \in R^{n}$ e suponha que $y=y^{*} \neq 0$ é um ponto de equilíbrio de interesse de (3.24). Para $i=1,2, \ldots, n$ a mudança de variáveis adequada para transladarmos o ponto de equilíbrio para origem é: 


$$
x_{i}=y_{i}-y_{i}^{*}
$$

e

$$
f\left(x_{i}\right)=G\left(y_{i}\right)-G\left(y_{i}^{*}\right)=G\left(x_{i}+y_{i}^{*}\right)-G\left(y_{i}^{*}\right) .
$$

Como $y_{i}=x_{i}+y_{i}^{*} \rightarrow \frac{d y_{i}}{d t}=\frac{d x_{i}}{d t}$ e $G\left(y_{i}\right)=f\left(x_{i}\right)+G\left(y_{i}^{*}\right)$, substituindo em (3.24), temos:

$$
\begin{gathered}
\frac{d x_{i}}{d t}=-d_{i}\left(x_{i}+y_{i}^{*}\right)+\sum_{j=1}^{n} b_{i j}\left[f_{j}\left(x_{j}\right)+G_{j}\left(y_{j}^{*}\right)\right] \\
\frac{d x_{i}}{d t}=-d_{i} x_{i}-d_{i} y_{i}^{*}+\sum_{j=1}^{n} b_{i j} f_{j}\left(x_{j}\right)+\sum_{j=1}^{n} b_{i j} G_{j}\left(y_{j}^{*}\right) \\
\frac{d x_{i}}{d t}=-d_{i} x_{i}+\sum_{j=1}^{n} b_{i j} f_{j}\left(x_{j}\right)+\left\{-d_{i} y_{i}^{*}+\sum_{j=1}^{n} b_{i j} G_{j}\left(y_{j}^{*}\right)\right\},
\end{gathered}
$$

observe que pela definição de ponto de equilíbrio a expressão dentro das chaves é zero.

Portanto,

$$
\frac{d x_{i}}{d t}=-d_{i} x_{i}+\sum_{j=1}^{n} b_{i j} f_{j}\left(x_{j}\right)
$$

Em relação à função $f$ temos:

$$
f_{i}\left(x_{i}\right)=G\left(x_{i}+y_{i}^{*}\right)-G\left(y_{i}^{*}\right) \rightarrow f_{i}(0)=G\left(y_{i}^{*}\right)-G\left(y_{i}^{*}\right)=0 \quad e \quad f_{i}^{\prime}=g_{i}^{\prime}>0 \quad(i=1,2, \ldots, n),
$$

assim com $f$ contínua nós temos:

$$
f \in F_{\infty}:=\left\{f \mid f(0)=0, \quad x_{i} f\left(x_{i}\right)>0, \quad x_{i} \neq 0\right\}
$$

Retomando a equação (3.3) do Problema de Lurie:

$$
\dot{y}_{i}=\sum_{j=1}^{n} \tilde{a}_{i j} y_{j}+\sum_{j=n-m+1}^{n} \tilde{b}_{i j} \tilde{f}_{j}\left(y_{j}\right) .
$$

Comparando a equação (3.25) com a equação (3.3) observamos que a rede neural de Hopfield é um caso especial de um sistema tipo Lurie com múltiplos controle, onde $\tilde{a}_{i j}=0, i \neq j, \tilde{a}_{i i}=d_{i}<0$, e $m=n$.

Portanto, com essa relação entre RNH e sistemas tipo Lurie a teoria e metodologia de sistemas tipo Lurie podem promover o estudo da estabilidade absoluta de redes neurais. Então, faz sentido perguntar quais são as condições necessárias e suficientes para um ponto de equilíbrio de (3.25) ser globalmente assintoticamente estável, ou seja, para ser absolutamente estável.

Considere a seguinte relação:

$$
\alpha_{i j}=\left\{\begin{array}{l}
\tilde{a}_{i j}, \quad i=1, \ldots n, \quad j=1, \ldots, n-m, \\
\tilde{b}_{i j}, \quad i=1, \ldots n, \quad j=n-m+1, \ldots, n .
\end{array}\right.
$$

Considere também o delta de Kronecker: 


$$
\delta_{i j}=\left\{\begin{array}{cc}
1, & i=j \\
0, & i \neq j
\end{array}\right.
$$

O teorema a seguir de 1993 devido a Liao [17], fornece condições suficientes para a estabilidade absoluta para o problema de Lurie descrito pela equação (3.3), bem como, pela RNH descrita por $(3.25)$.

Teorema 3.3. A solução zero de (3.3) ou (3.25) é absolutamente estável se as condições de um dos seguintes conjuntos forem satisfeitas:

1) $\tilde{a}_{i i}<0$ para $i=1, \ldots, n$, e a matriz $n_{x} n$ onde $\left((-1)^{\delta_{i j}}\left|\tilde{a}_{i j}\right|\right)$ é Hurwitz.

2) Existe uma constante $k_{l}>0$ para $l=n-m+1, \ldots, n$ tal que

$$
\left\{\begin{array}{c}
k_{l} \tilde{b}_{l l} \leq \tilde{a}_{l l}, \quad k_{l}\left|\tilde{b}_{i l}\right|<\left|\tilde{a}_{i l}\right|, \quad \text { para } \quad l=n-m+1, \ldots, n, \quad i=1, \ldots, n, \quad i \neq l, \\
\text { ou } \\
k_{l} \tilde{b}_{l l}<\tilde{a}_{l l}, \quad k_{l}\left|\tilde{b}_{i l}\right| \leq\left|\tilde{a}_{i l}\right|, \quad \text { para } \quad l=n-m+1, \ldots, n, \quad i=1, \ldots, n, \quad i \neq l,
\end{array}\right.
$$

ou

1') $\tilde{a}_{i i}<0$ para $i=1, \ldots, n$, e a matriz $n_{x} n$ onde $\left((-1)^{\delta_{i j}}\left|\alpha_{i j}\right|\right)$ é Hurwitz.

2') Existe uma constante $k_{l}>0$ para $l=n-m+1, \ldots, n$ tal que

$$
\left\{\begin{array}{c}
k_{l} \tilde{a}_{l l} \leq \tilde{b}_{l l}, \quad k_{l}\left|\tilde{a}_{i l}\right|<\left|\tilde{b}_{i l}\right|, \quad \text { para } \quad l=n-m+1, \ldots, n, \quad i=1, \ldots, n, \quad i \neq l, \\
\text { ou } \\
k_{l} \tilde{a}_{l l}<\tilde{b}_{l l}, \quad k_{l}\left|\tilde{a}_{i l}\right| \leq\left|\tilde{b}_{i l}\right|, \quad \text { para } \quad l=n-m+1, \ldots, n, \quad i=1, \ldots, n, \quad i \neq l,
\end{array}\right.
$$

Demonstração. A condição 1) implica que existem constantes $r_{i}>0, i=1, \ldots, n$, tal que

$$
r_{j} \tilde{a}_{j j}+\sum_{i=1, i \neq j}^{n} r_{i}\left|\tilde{a}_{i j}\right|<0, \quad j=1, \ldots, n .
$$

A condição 2) implica que

$$
r_{l} \tilde{b}_{l l}+\sum_{i=1, i \neq l}^{n}\left|r_{i} \tilde{b}_{i l}\right| \leq\left[r_{l} \tilde{a}_{l l}+\sum_{i=1}^{n} r_{i}\left|\tilde{a}_{i l}\right|\right] / k_{l}<0, \quad l=n-m+1, \ldots, n .
$$

Constroi-se a função de Lyapunov

$$
V=\sum_{i=1}^{n} r_{i}\left|y_{i}\right|
$$

então

$$
\begin{gathered}
\left.D^{+} V(y)\right|_{3.3} \leq \sum_{j=1}^{n}\left[r_{j} \tilde{a}_{j j}+\sum_{i=1, i \neq j}^{n} r_{i}\left|\tilde{a}_{i j}\right|\right]\left|y_{j}\right| \\
+\sum_{l=n-m+1}^{n}\left[r_{l} \tilde{b}_{l l}+\sum_{i=1, i \neq l}^{n} r_{i}\left|\tilde{b}_{i l}\right|\right]\left|\tilde{f}_{l}\left(y_{l}\right)\right|<0 \quad \text { para } \quad y \neq 0,
\end{gathered}
$$

Consequentemente, a solução zero de (3.3) ou (3.25) é absolutamente estável. 1') e 2') pode ser provado analogamente. 
Exemplo 3.2. Vamos estudar a estabilidade absoluta do seguinte sistema tipo Lurie com 2 controles [18]:

$$
\left\{\begin{array}{l}
\dot{x}_{1}=-4 x_{1}+2 x_{2}+x_{3}+2 f_{2}\left(x_{2}\right)+2 f_{3}\left(x_{3}\right) \\
\dot{x}_{2}=2 x_{1}-3 x_{2}+x_{3}-4 f_{2}\left(x_{2}\right)-2 f_{3}\left(x_{3}\right) \\
\dot{x}_{3}=-2 x_{1}+x_{2}-3 x_{3}+f_{2}\left(x_{2}\right)-7 f_{3}\left(x_{3}\right)
\end{array}\right.
$$

Onde $f_{2}, f_{3} \in F_{\infty}$

Temos:

$$
\begin{aligned}
{\left[\begin{array}{lll}
a_{11} & a_{12} & a_{13} \\
a_{21} & a_{22} & a_{23} \\
a_{31} & a_{32} & a_{33}
\end{array}\right] } & =\left[\begin{array}{ccc}
-4 & 2 & 1 \\
2 & -3 & 1 \\
-2 & 1 & -3
\end{array}\right], \\
{\left[\begin{array}{ll}
b_{12} & b_{13} \\
b_{22} & b_{23} \\
b_{32} & b_{33}
\end{array}\right] } & =\left[\begin{array}{cc}
2 & 2 \\
-4 & -2 \\
1 & -7
\end{array}\right]
\end{aligned}
$$

A matriz $n_{x} n$ da condição 1 do teorema (3.3) é dada por

$$
\left[\begin{array}{ccc}
-4 & 2 & 1 \\
2 & -3 & 1 \\
2 & 1 & -3
\end{array}\right]
$$

e tem os seguintes autovalores $-5.64575 ;-0.35425 ;-4.00000$, portanto a matriz é Hurwitz que satisfaz a condição 1.

Em relação à condição 2. temos

$$
\begin{gathered}
0>a_{l l}>b_{l l}, \quad\left|a_{i l}\right|=\left|b_{i l}\right|, \quad i=1,3, \quad l=2, \quad \text { com } \quad k_{2}=1 \\
0>a_{l l}>k b_{l l}, \quad\left|a_{i l}\right|=k\left|b_{i l}\right|, \quad i=1,2, \quad l=3, \quad \text { com } \quad k_{3}=\frac{1}{2}
\end{gathered}
$$

Assim, as condições do teorema (3.3) são satisfeitas, portanto a solução zero do sistema (3.26) é absolutamente estável.

Exemplo 3.3. Vamos analizar a seguinte rede neural [9, 38]:

$$
\left\{\begin{array}{l}
\dot{u}_{1}=-1.4 u_{1}+1.2 g_{2}\left(u_{2}\right) \\
\dot{u}_{2}=-1.1 u_{2}+g_{1}\left(u_{1}\right)
\end{array},\right.
$$

onde $\quad g_{i}\left(u_{i}\right)=\frac{2}{\pi} \arctan \left(\lambda \frac{\pi}{2} u_{i}\right), \quad i=1,2$.

$$
\begin{gathered}
{\left[\begin{array}{ll}
\tilde{a}_{11} & \tilde{a}_{12} \\
\tilde{a}_{21} & \tilde{a}_{22}
\end{array}\right]=\left[\begin{array}{cc}
-1.4 & 0 \\
0 & -1.1
\end{array}\right],} \\
\alpha_{i j}=\left[\begin{array}{ll}
\tilde{b}_{11} & \tilde{b}_{12} \\
\tilde{b}_{21} & \tilde{b}_{22}
\end{array}\right]=\left[\begin{array}{cc}
0 & 1.2 \\
1 & 0
\end{array}\right] .
\end{gathered}
$$

Aplicando o primeiro conjunto de condições do teorema (3.3), temos:

A condição 1 do teorema é satisfeita, pois $\tilde{a}_{i i}<0$ e a matriz $\left((-1)^{\delta_{i j}}\left|\alpha_{i j}\right|\right)$ é Hurwitz. 
Em relação à condição 2, temos:

$$
k \tilde{b}_{11} \leq \tilde{a}_{11} \rightarrow k_{1}(0) \leq(-1.4) .
$$

A desigualdade $k_{1}(0) \leq(-1.4)$ mostra que não existe $k_{1}$ que satisfaz tal condição.

Aplicando o segundo conjunto de condições do teorema (3.3), temos:

A condição 1' não é satisfeita, pois a matriz $\left((-1)^{\delta_{i j}}\left|\alpha_{i j}\right|\right)$ não é Hurwitz, isto é, possui autovalores iguais a 1.0954 e -1.0954 .

Portando, pelo teorema (3.3) não podemos tirar conclusões a respeito da estabilidade absoluta do sistema em análise.

Por outro lado, utilizando uma análise minuciosa efetuada por Zak [38] a respeito da estabilidade da RNH em questão, temos que o sistema possui três pontos de equilíbrio a saber:

$$
u^{* 1}=\left(\begin{array}{l}
-0.4098 \\
-0.4245
\end{array}\right), \quad u^{* 2}=\left(\begin{array}{l}
0 \\
0
\end{array}\right), \quad \text { e } \quad u^{* 3}=\left(\begin{array}{c}
0.4098 \\
0.4245
\end{array}\right),
$$

Zak em sua análise conclui que os equilíbrios $u^{* 1}, u^{* 3}$ são assintoticamente estáveis, enquanto que o equilíbrio $u^{* 2}$ é instável. Podemos observar isso conforme a figura a seguir

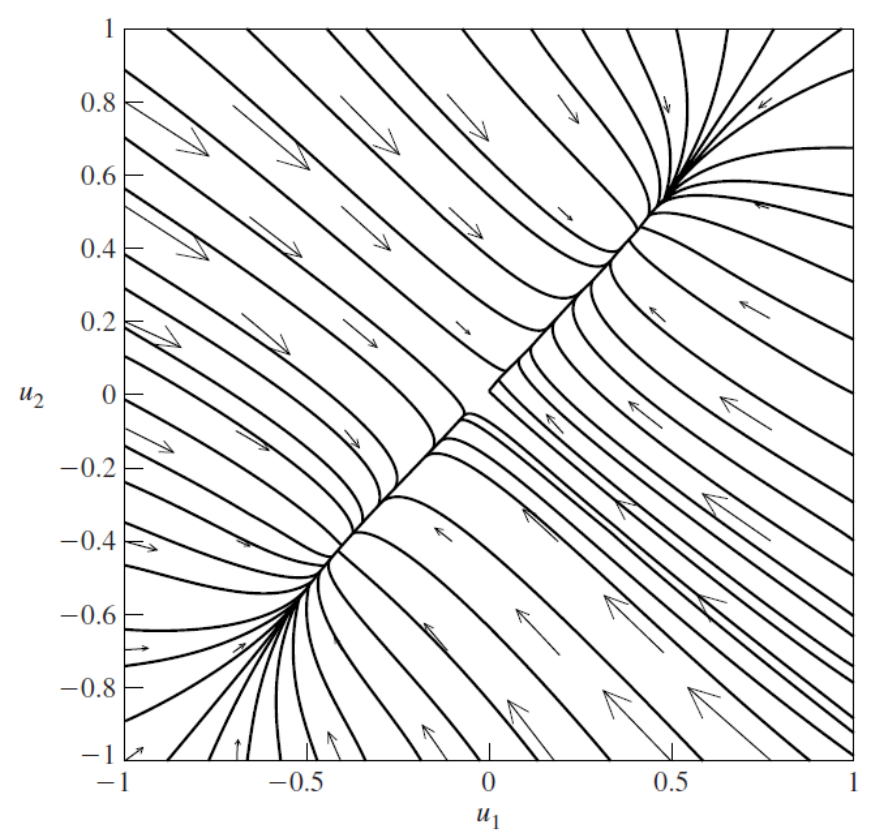

Figura 3.7: Plano de fase da RNH do exemplo (3.3) com os pontos de equilíbrio $u^{* 1}, u^{* 2}$ e $u^{* 1}$

Assim, pelo fato do exemplo anterior possuir três pontos de equilíbrio a estabilidade absoluta não pode ser considerada, pois é necessário que o ponto de equilíbrio seja único, portanto o teorema (3.3) faz bem seu papel, ou seja, não conclui estabilidade absoluta para a RNH do exemplo (3.3).

Exemplo 3.4. Considere a rede neural com dois neurônios [23]:

$$
\left\{\begin{array}{l}
\dot{u}_{1}=-u_{1}-2 g_{1}\left(u_{1}\right)+1.5 g_{2}\left(u_{2}\right)+I_{1} \\
\dot{u}_{2}=-u_{2}+1.5 g_{1}\left(u_{1}\right)-2 g_{2}\left(u_{2}\right)+I_{2}
\end{array}\right.
$$

Onde $\quad g_{i}\left(u_{i}\right)=\tanh \left(u_{i}\right), \quad R_{i}=C_{i}=1, \quad I_{i}=0, \quad i=1,2, \quad T_{i i}=-2, \quad T_{12}=T_{21}=1.5$. 


$$
\begin{gathered}
{\left[\begin{array}{cc}
\tilde{a}_{11} & \tilde{a}_{12} \\
\tilde{a}_{21} & \tilde{a}_{22}
\end{array}\right]=\left[\begin{array}{cc}
-1 & 0 \\
0 & -1
\end{array}\right],} \\
\alpha_{i j}=\left[\begin{array}{ll}
\tilde{b}_{11} & \tilde{b}_{12} \\
\tilde{b}_{21} & \tilde{b}_{22}
\end{array}\right]=\left[\begin{array}{ll}
-2 & 1.5 \\
1.5 & -2
\end{array}\right] .
\end{gathered}
$$

Aplicando o segundo conjunto de condições do teorema (3.3), temos:

A condição 1'do teorema é satisfeita, pois $\tilde{a}_{i i}<0$ e a matriz $\left((-1)^{\delta_{i j}}\left|\alpha_{i j}\right|\right)$ possui autovalores iguais a -3.5 e -0.5 portanto ela é Hurwitz.

Em relação à condição 2', temos:

$$
\begin{aligned}
& k \tilde{a}_{11} \leq \tilde{b}_{11} \rightarrow k_{1}(-1) \leq(-2), \quad k_{1}\left|\tilde{a}_{21}\right|<\left|\tilde{b}_{21}\right| \rightarrow k_{1}|0|<|1.5|, \quad \text { para } \quad l=1, \quad i=2 ; \\
& k \tilde{a}_{22} \leq \tilde{b}_{22} \rightarrow k_{2}(-1) \leq(-2), \quad k_{2}\left|\tilde{a}_{12}\right|<\left|\tilde{b}_{12}\right| \rightarrow k_{2}|0|<|1.5|, \quad \text { para } \quad l=2, \quad i=1 ;
\end{aligned}
$$

tomando $k_{1}=k_{2}=2$ a condição 2' é satisfeita, portando o ponto de equilíbrio do sistema é absolutamente estável. 


\section{Considerações Finais}

Gostaríamos de fazer algumas considerações que julgamos convenientes, bem como, trazer sugestões de futuras pesquisas e estudos.

Sobre o primeiro capítulo Conjectura de Aizerman é um assunto que gera a possibilidade de um grande aprendizado, pois faz uso de diversas ferramentas importantes dentro da teoria da estabilidade e controle, bem como, no decorrer de sua pesquisa desenvolveu novas técnicas e métodos dentro da Matemática Aplicada, embora a conjectura já esteja resolvida, ou seja, foi validada para dimensão 2 e não válidada para dimensões superiores, então sugerimos seu estudo e compreensão em cada caso. Ainda nesse capítulo é comentado sobre uma metodologia que utiliza funções de Lyapunov não necessariamente com derivada semi-definida negativa, assim temos um conceito e ferramenta interessante que vale a pena ser conhecido.

No segundo capítulo ressaltamos o exemplo do sistema de controle automático de aeronaves, pois, embora tenha sido estudado há mais de 70 anos pelo próprio Lurie, esse problema ainda é considerado e está em aberto, sendo fruto de diversas pesquisas. O teorema 2.3 foi um resultado que obtemos a partir da sugestão de [7], embora seja para o caso de um único controle e resultados semelhantes já tenham sido apresentados, a forma de abordagem do problema e a prova de seu resultado é algo que não encontramos na literatura e ainda pode ser explorado para a obtenção da condição necessária.

Finalmente, no capítulo 3 temos a apresentação do Problema de Lurie para múltiplos controles, o qual ainda não está resolvido por completo no sentido de apresentação de condições necessária e suficientes para a estabilidade absoluta. Sobre a rede de Hopfield, ela é fruto de intensa pesquisa em relação a sua estabilidade, aqui procuramos entender um pouco sua dinâmica e fizemos consideração a respeito de sua estabilidade. É bem interessante conhecê-la de forma aprofundada pois na seção 3.5 é proposta uma modelagem do mal de Alzheimer utilizando-se da Rede Neural de Hopfield, problema que está em aberto podendo ser um interessante objeto de pesquisa. Nos casos dos teoremas 3.2 e 3.3 consideramos conveniente uma melhor averiguação de sua prova, pois na bibliografia o qual encontramos [17, 18], necessitamos fazer algumas correções no seu enunciado para apresentar nesse trabalho.

Estudos têm mostrado que muitas vezes quando se conclui estabilidade absoluta, é também concluído estabilidade absoluta exponencial. Porém é algo ainda em pesquisa intensa. Na pesquisa bibliográfica que fizemos, referências como $[5,6,10,18,23,38]$ estão bem à frente na pesquisa do Problema de Lurie e estabilidade absoluta da Rede Neural de Hopfield, e que podem servir de referências para futuras pesquisas. 


\section{Referências Bibliográficas}

[1] Aizerman M.A. (1947): On the Effect of Nonlinear Functions of Several Variables on the Stability of Automatic Control Systems. Autom. i Telemekh, VIII(1). 12

[2] Barbashin-Krasovskii, E. A. e N.N. (1952): On the Stability of Motion in the Large. Dokl. Akad. Nauk. SSSR, 86, 453-456. 11

[3] Braga, A. P., Carvalho, A. C. P. L., Ludemir, T. B. (2007). Redes Neurais Artificiais: teoria e aplicações. LTC. $2^{\mathrm{a}}$ edição. 37

[4] Fiqueiredo, D. G. e Neves, A. F. (2007): Equações Diferenciais Aplicadas. IMPA. 2, 5

[5] Forti, M., Manetti, S., Marini, M. (1994): Necessary and Sufficient Condition for Absolute Stability of Neural Networks. IEEE Trans. Circuits Syst., 41, 491-494. 49

[6] Forti, M., Manetti, S., Marini, M., Liberatore, S. (1994): On Absolute Stability of Neural Networs. IEEE Trans. Circuits Syst., 6, 241-244. 49

[7] Guzman, M. (1975): Equaciones Diferenciales Ordinarias, Teoria de estabilidad y control. Alhambra. 11, 15, 23, 49

[8] Hahn, W. (1967): Stability of Motion. Springer.

[9] Hopfield. J. J. (1984): Neurons With Graded Response Have Collective Computacional Properties Like Those of Two-State Neurons. Proc. Natl. Acad. Sci. USA. 36, 46

[10] Kaskurewicz, E., Bhaya, A. (1995): Comments on Necessary and Sufficient Condition for Absolute Stability of Neural Network. IEEE Trans. Circuits Syst., 42,497-499. 49

[11] Krasovskii, N. N. (1953): On the Stability of the solutions of a System of Two Differential Equations. Prikl. Matem. i Mekh., XVII(6). 12

[12] Krasovskii, N. N. (1959): Problem in Motion Stability. Fizmatgiz. Moscow (em Russo); Tradução em inglês (1963) Stanford University Press, Stanford. 25

[13] Khalil, H. K. (2002): Nonlinear Systems. Prentice Hall. 3ed. New Jersey. 32

[14] LaSalle, J.P. (1960): Some Extensions of Liapunov's Second Method. IRE Trans. on Circuit Theory. CT-7:520 527. 9

[15] LaSalle, J. P. (1961): Stability by Liapounovs Direct Method. Academic Press, New York. 11

[16] Lefschtz, S. (1965): Stability of Nonlinear Control Systems. Academic Press, New York. 21

[17] Liao, X. (1993) Absolute Stability of nonlinear Control Systems. Kluwer Academic China Science Press. Beijing. ix, 45, 49

[18] Liao, X. and Yu, P. (2008): Absolute Stability of Nonlinear Control Systems. Springer. ix, 15, $19,23,25,29,30,32,33,42,46,49$ 
[19] Liao, X. X.(2001): Mathematical Theory and Application of Stability, Huazhong Normal University Press, Wuhan (in Chinese). 23

[20] Liao, X., Xu, P., Yu, P. (2006): Absolute Stability of Hopfield Neural Network. Springer. ix

[21] Liao, X. X., Shu, W. H., Wu, W. H. (1993): On Absolute Stabibity of Nonliiinear Nonstationary Control Systems. J. Cent. China Norm. Univ., 27, 273-279.

[22] Liao, X. X., Wang, X. J., Shu, W. H., Wu, W. H. (1996): Absolute Stability of Control System With Multi-Nonlinear Feedback Terms. Acta Math. Sin. 16, 302-307.

[23] Liao, X., Wang, L., Yu, P. (2007): Stability of Dynamical Systems. Elsevier. Amsterdam. 41, 47,49

[24] Lurie, A. I., Postnikov, V. N. (1945): On the theory of Stability of Control Systems. Prikl. Mat. i Mehk. IX(5). 17, 18, 20, 22

[25] Monteiro, L. H. A. (2006): Sistemas Dinâmicos. Livraria da Física 2ed. 2, 42

[26] Monteiro, J. L. R., Netto, M. L., Andina, D., Peláez, J. R.: Using Neural Networks to Simulate the Alzheimer's Disease. Proceedings of the 2008 World Automation Congress, v. 1, p. 712-717 (2008). 42

[27] Pliss, V. A. (1958): O Problema de Aizerman para dimensão 3. Dokl. Akad. Nauk. Tom 121, n.3 (em russo). 12

[28] Popov, V. M. (1961): Absolute sttability of nonlinear systems of automatic control. Remote Control, 22(8):857-875. 25

[29] Ogata, K. (2003): Engenharia de Controle Moderno. 4 ed. Pearson Prentice Hall. 17, 19

[30] Ortega, J. M., Rheinboldt, W. C. (1970): Iterative Solution of Nonlinear Equations in Several Variables. Academic Press, New York. 33

[31] Pinheiro, R. F. (2010): Estudo da Conjectura de Aizerman em Dimensão 2 e Um Contraexemplo em Dimensão 4. Universidade de São Paulo. 2, 12

[32] Rasvan, V. (2011): Systems With Monotone and Slope Restricted Nonlinearities. Tatra Mt. Math. Publ. Romênia. 17, 18

[33] Rodrigues, H. M., et al (2000). On the Invariance Priciple, Generalizations and Applications to Synchronism. Trans. on Circuits and Systems I; Fundamental Theory and Applications 47(5): 730-739. 11

[34] State, C. A. (2013): Longitudinal Absolute Stability of a BWB Aircraft-Pilot System with Saturated Actuator Model. INCAS BULLETIN, Volume 5, Issue 3/ 2013, pp. 115 - 125 ISSN 2066 - 8201. University of Craiova. 18

[35] Xie, H. M.(1986): Theory and Application of Absolute Stability. Chinese Science Press. Beijing (in Chinese). 15, 23, 26

[36] Willems, J. C. (1971): The Analysis of Feedback Systems. The Massachusetts Institute of Technology. MIT Press. Massachussetts.

[37] Ye, B.Y.(1987): The NASC for the Absolute Stability of Direct Control Systems of Second Order. J. Math., 7, 48-54. (in Chinese). 25

[38] Zak, S. H. (2003): Systems and Control. Oxford University Press. New York. 8, 41, 46, 47, 49 
[39] Zhang, W. (1989): The Criterions for Absolute Stability of Direct Control Systems of Lurie Type. Appl. Math. Mech., 10, 955-967. 26

[40] Zhao, S. X. (1979): On the Absolute Stability of Direct Control System. Acta Math. Sin., 22, 404-419 (in Chinese). 30

[41] Zhao, W., Qiao, Q., Wang, D. (2009): A Hippocampus CA3 Model with Autoassociative and Heteroassociative Memory Functions. Proceedings of the 2nd International Conference on Biomedical Engineering and Informatics, v.1, p. 1-4. 42

[42] Zhilin, P. A. (2001): A. I. Lurie - Works on Mechanics. Proceedings of XXVIII Summer School - Conference "Advanced Problems in Mechanics", St. Petersburg, Russia. 